NBER WORKING PAPER SERIES

\title{
CAN STATES TAKE OVER AND TURN AROUND SCHOOL DISTRICTS? EVIDENCE FROM LAWRENCE, MASSACHUSETTS
}

\author{
Beth E. Schueler \\ Joshua Goodman \\ David J. Deming \\ Working Paper 21895 \\ http://www.nber.org/papers/w21895 \\ NATIONAL BUREAU OF ECONOMIC RESEARCH \\ 1050 Massachusetts Avenue \\ Cambridge, MA 02138 \\ January 2016
}

We owe thanks to Carrie Conaway at the Massachusetts Department of Elementary and Secondary Education, Julie Albino, Mary Lou Bergeron, David Clement, Sara D'Allesandro, Michael Kennealy, Seth Racine, Kristyn Rice, Jeffrey Riley, and Mary Toomey at the Lawrence Public Schools, Steven Poftak at the Rappaport Institute of Greater Boston, and Martin West at the Harvard Graduate School of Education. Beth Schueler's work on this paper has been supported by funding from the Rappaport Institute for Greater Boston and the Harvard Graduate School of Education Dean's Summer Fellowship. Address correspondence to Beth E. Schueler, beth_schueler@mail.harvard.edu, Joshua S. Goodman, joshua_goodman@hks.harvard.edu, or David J. Deming, david_deming@gse.harvard.edu. The views expressed herein are those of the authors and do not necessarily reflect the views of the National Bureau of Economic Research.

NBER working papers are circulated for discussion and comment purposes. They have not been peerreviewed or been subject to the review by the NBER Board of Directors that accompanies official NBER publications.

(C) 2016 by Beth E. Schueler, Joshua Goodman, and David J. Deming. All rights reserved. Short sections of text, not to exceed two paragraphs, may be quoted without explicit permission provided that full credit, including $\odot$ notice, is given to the source. 
Can States Take Over and Turn Around School Districts? Evidence from Lawrence, Massachusetts Beth E. Schueler, Joshua Goodman, and David J. Deming

NBER Working Paper No. 21895

January 2016

JEL No. I20,I21,I28

\begin{abstract}
$\underline{\text { ABSTRACT }}$
The Federal government has spent billions of dollars to support turnarounds of low-achieving schools, yet most evidence on the impact of such turnarounds comes from high-profile, exceptional settings and not from examples driven by state policy decisions at scale. In this paper, we study the impact of state takeover and district-level turnaround in Lawrence, Massachusetts. Takeover of the Lawrence Public School (LPS) district was driven by the state's accountability system, which increases state control in response to chronic underperformance. We find that the first two years of the LPS turnaround produced large achievement gains in math and modest gains in reading. Our preferred estimates compare LPS to other low income school districts in a differences-in-differences framework, although the results are robust to a wide variety of specifications, including student fixed effects. While the LPS turnaround was a package of interventions that cannot be fully separated, we find evidence that intensive small-group instruction led to particularly large achievement gains for participating students.

Beth E. Schueler

Harvard Graduate School of Education

Cambridge, MA 02138

bes674@mail.harvard.edu

Joshua Goodman

Harvard Kennedy School

79 JFK Street

Cambridge, MA 02138

and NBER

joshua_goodman@hks.harvard.edu

David J. Deming

Harvard Graduate School of Education

Gutman 411

Appian Way

Cambridge, MA 02139

and NBER

david_deming@gse.harvard.edu
\end{abstract}




\section{SCHOOL AND DISTRICT TURNAROUND}

Turning around chronically under-performing schools and districts has long been an elusive goal, despite prioritization at the highest levels of government (Gewertz, 2009). In recent years, considerable Federal resources have been devoted toward this end. The Obama administration's signature education initiative, Race to the Top, awarded $\$ 4.35$ billion to states in competitive grant funding, based on six criteria, one of which was the state's plans for turning around their lowest achieving schools (Smarick, 2010). This was on top of $\$ 3$ billion in new funding for School Improvement Grants (SIG), aimed at turning around the lowest-performing five percent of public K-12 schools, which was also funded by the American Recovery and Reinvestment Act (Dee, 2012). ${ }^{1}$

At the state level, there is considerable variation across accountability models in the policy response to chronic underperformance. Most recently, the U.S. Department of Education (U.S. DOE) through its Elementary and Secondary Education Act Flexibility Program has encouraged states to adopt tiered accountability systems targeting the lowest performers for intensive interventions. The U.S. DOE has held up the Massachusetts system as an exemplar (U.S. DOE, 2012). This system has three distinct features. First, it classifies schools and districts into five levels based on performance. Second, it requires low-performing schools and districts to implement rapid improvement plans. Third, it allows the State to takeover schools and districts at the very lowest levels of achievement (U.S. DOE, 2012).

Nationally, several high-profile state takeovers of underperforming districts have resulted in the implementation of a "portfolio management model" (PMM) approach to district organization and improvement. With PMM, the central office oversees and holds accountable a supply of schools that are managed by a diverse set of operators such as charter management organizations, nonprofit groups, and the district itself (Hill, Campbell \& Gross, 2012). State-managed portfolio models range from Louisiana's Recovery School District in which management of nearly all schools has been handed over to charter school operators to Tennessee's Achievement School District in which district governance is divorced from geography and low-performing schools from across the State are placed in a single district.

For portfolio districts, the capacity of state departments of education could be a key determinant of the success of turnaround efforts. ${ }^{2}$ Examining state turnarounds of districts between 1992 and 2000, Wong and Shen $(2002,2003)$ found that states have successfully improved district financial management but have had less success with improving student academic outcomes. These turnarounds predate, however, No Child Left Behind (NCLB) and thus did not occur in a policy context with standardized performance information and high-stakes testing.

Beginning in Fall 2012, Lawrence Public Schools (LPS) was taken over by the Massachusetts state Department of Elementary and Secondary Education (DESE). The takeover was specified

\footnotetext{
${ }^{1}$ This was beyond the $\$ 546$ million that had previously been appropriated for this purpose.

${ }^{2}$ Katrina Bulkley has argued that the portfolio management approach sits at the intersection of market-based reform, standards-based reform, and reform geared toward school-level differentiation. However, local governmental capacity plays a central role in portfolio management given that the district is responsible for contracting with individual school managers, judging their success, and holding them accountable for results (Bulkley, 2010).
} 
as the final step in a policy process that began with chronic underperformance and ended with the classification of LPS as a Level 5 district, the lowest rating in the state's accountability system. The Achievement Gap Act - signed into Massachusetts state law in 2010 - granted the State Board and Commissioner of Education the authority to intervene and take control of Level 5 school districts. LPS was the first Massachusetts school district to be taken over under the Achievement Gap Act.

We find that LPS students exposed to the first two years of the state's takeover score 0.17 to 0.19 standard deviations higher on math exams and 0.02 to 0.03 standard deviations higher on ELA exams compared to demographically similar students in other Massachusetts districts. Our results are robust to controlling for student fixed effects, which suggests that compositional changes in the LPS student body cannot explain our findings. We find suggestive evidence that participation in "Acceleration Academies" - an intensive, targeted instructional program that was administered to some students over vacation breaks - can explain a large share, but not the entirety, of the math impact and all of the ELA impact of the LPS turnaround on student achievement.

Our work contributes to two recent strands of research concerning school turnarounds. First, a number of recent papers have examined the impact of a variety of efforts to turn around individual schools. Dee (2012) uses a regression discontinuity approach to show that Federal School Improvement Grants (SIG) awarded as part of the 2009 American Recovery and Reinvestment Act improved achievement among schools adopting the Federal turnaround model. Papay (2015) sees substantial achievement gains in Massachusetts schools eligible for SIG funding and required to choose from among a variety of school improvement models. Charter schools also provide a model for turnaround. Abdulkadiroglu et al. (2014) find large impacts in both math and reading from converting underperforming traditional public schools into charter schools in Boston and New Orleans. Fryer (2014) shows that injecting best practices from charter schools into traditional public schools boosts math, though not reading, achievement.

One contribution of our paper is to examine the turnaround of an entire district, rather than individual schools. Much less is known about the effects of district-level reforms, which may be more likely than school-specific reform to create the conditions and capacity for the lowestperforming schools to have long-run success (Zavadsky, 2013; Johnson, Marietta, Higgins, Mapp \& Grossman, 2015). Recent evidence is consistent with the idea that districts play an important role in student achievement, beyond that which school-level factors alone can explain (Chingos et al., 2015).

Second, a few recent papers have explored entire districts undergoing a variety of turnaround efforts. Harris and Larsen (2016), for example, document substantial achievement gains across the entire New Orleans school district following the wide-ranging reforms enacted post-Katrina. Strunk et al. (2012) showed mixed results from Los Angeles' attempt to at a portfolio model of reform for its lowest-performing schools. Gill et al. (2007) show that the state's takeover of Philadephia's school district in 2002, which turned over control of many schools to private operators, had little impact on student achievement.

Many of these district-level turnaround efforts were, however, exceptional cases, largely focused on allowing outside operators to take over large numbers of schools. The LPS turnaround was, in 
contrast, only in small part driven by such outside operators. The turnaround effort was a policy response stemming directly from state law and likely to be repeated in other local contexts. While LPS was the first Massachusetts school district to be taken over by the state, the Massachusetts Board of Elementary and Secondary Education voted in the spring of 2015 to take over the Holyoke Public Schools as well. Our paper's second contribution is thus to provide the first evidence of the impact of accountability-based turnaround policies at scale. We hope that the lessons learned here can thus inform policymaking in other states.

\section{THE CONTEXT: LAWRENCE, MASSACHUSETTS}

Lawrence is a mid-sized industrial city about 30 miles north of Boston that is considered, based on several measures, to be one of the most economically disadvantaged cities in the State of Massachusetts. From 2009 to 2013, median household income was $\$ 32,851$ and the poverty rate was 29.2 percent. Roughly 11 percent of residents over the age of 25 held at least a Bachelor's degree. Nearly 40 percent of Lawrence's population was foreign born (U.S. Census, 2015). Most of these residents have immigrated from either the Dominican Republic or Puerto Rico. Lawrence Public Schools (LPS) enrolled approximately 13,000 students in 28 schools as of 2011.

Table 1 presents descriptive statistics for the Lawrence student population. Relative to the rest of Massachusetts, Lawrence students are far more likely to be low-income and Hispanic. Leading up to the turnaround, roughly 80 percent of LPS students were learning English as a second language, making Lawrence a particularly relevant case given our nation's growing population of ESL students. Prior to the takeover, LPS students scored about 0.75 standard deviations below the state average on ELA and Math exams. LPS students also score somewhat lower than students in other districts with a predominately low-income population.

The district has a long history of chronic underperformance, but the State took particular notice after reviewing results for the 2010-11 school year. Lawrence was in the bottom five districts in the State based on the percentage of students considered proficient on the ELA and math Massachusetts Comprehensive Assessment System (MCAS) exams. Three quarters of the schools in the districts experienced declines in achievement between 2009-10 and 2010-11 and only about half of all students were graduating within four years.

In the fall of 2011, based on these performance measures, the Massachusetts Board of Elementary and Secondary Education classified LPS as a Level 5 district, the lowest rating in its one through five tiered accountability system, and placed the District into receivership. In January of 2012, the State appointed a Receiver: Jeffrey Riley, a former Boston Public Schools teacher, principal and deputy superintendent. Riley was given all the authority of the previous Superintendent and School Committee. The Achievement Gap Act also gave the Receiver broad discretion to alter district-wide policies including the collective bargaining agreement, to require staff to reapply for their positions, and to unilaterally extend the school day or year district-wide. The Receiver spent the Spring of 2012 gathering information, recruiting and hiring a central office team, visiting schools, interviewing principals, and planning for the 2013 academic year. 
Receivership did not automatically come with large amounts of additional funding. According to estimates from the Massachusetts Department of Elementary and Secondary Education (MA DESE), per pupil spending increased only slightly in the first year of the turnaround from $\$ 13,272$ in 2012 to $\$ 13,852$ in 2013 . This was relatively similar to the state average for 2013 of $\$ 14,021$ (MA DESE, 2015). However, in the second year of the turnaround, LPS did receive more than \$2 million in Race to the Top funding and more than \$3 million in School Redesign Grants through the Federal School Improvement Grant program (Education Research Services, 2015). In addition, LPS has received some private funding, from individual donors and foundations, to support special programs such as the Acceleration Academies.

\section{THE LAWRENCE PUBLIC SCHOOLS TURNAROUND}

The Receiver began implementing turnaround efforts in the 2012-13 school year and the turnaround intensified over time. In this paper, we present results from the first two years of the turnaround implementation: 2013 (year one) and 2014 (year two). In the follow section, we outline the five primary components of the turnaround strategy, specifying the changes that occurred over time. This description is also summarized in Figure 1.

Expectations. First, the District attempted to raise expectations for students and staff. In the Spring of 2012, the Receiver released a turnaround plan that laid out ambitious performance targets, including 1) doubling the number of schools with Student Growth Percentiles ${ }^{3}$ greater than 50 in year one, 2) moving from $22^{\text {nd }}$ to one of the top five ranked Massachusetts Gateway districts ${ }^{4}$ in ELA and math proficiency and graduation by year three, and 3) closing the gap with the rest of the State in ELA and math proficiency and graduation within five to seven years (MA DESE, 2012).

Autonomy and Accountability. Second, the District attempted to reduce spending on the central office and increase school-level autonomy. The Receiver cut the central office budget, moving $\$ 1.6$ million to the school level in year one and an additional \$5 million in year two (Education Research Services, 2015) in an effort to push funds to the school level and shift to a more service-oriented approach to district-school relations. This is consistent with other improved districts that have moved from a compliance to a school-support focus (Supovitz, 2006) and provide a differentiated menu of services based on individual schools' needs (Honig, 2013).

While the overall goal was increased autonomy, the District provided differentiated levels of autonomy and supports to schools based on each school's prior performance and perceived capacity. The District gave schools that were highest performing prior to the turnaround, such as the Level 1 South Lawrence East Elementary and Frost Middle School, the highest levels of autonomy to continue operating as they saw fit. For the lowest performing schools, the District began handing over management to independent operators. These organizations were then given substantial operational autonomy. Schools in the middle, based on prior performance, were provided with the least autonomy and the most intensive central office supports.

\footnotetext{
${ }^{3}$ Massachusetts Department of Elementary and Secondary Education's growth model. More information can be found at: http://www.doe.mass.edu/mcas/growth/

${ }^{4}$ Massachusetts Gateway districts are located in 26 Gateway Cities that are characterized as midsized urban centers with historical economic success, but persistent contemporary social and economic challenges.
} 
The ultimate result could be thought of as a portfolio management model of district organization in that the central office oversees a diverse set of school operators that range, in this case, from charter management organizations to local non-profits to the Lawrence Teachers Union. However, the Lawrence model is different from many portfolio management districts in that it does not manage schools of choice. Even the Lawrence schools that are now operated by organizations that have historically run charter schools are non-charter public schools with open enrollment policies and unionized teachers.

For example, the Community Group, a Lawrence-based early childhood education and charter school operator, began managing the Kindergarten and $1^{\text {st }}$ grade at Arlington Elementary (now Community Day Arlington) in year one. In year two, the Community Group assumed responsibility for grades K-4. Spark Academy, a new organization led by a duo of educators, took over the $5^{\text {th }}$ grade at South Lawrence East Middle (now Spark Academy) in year one to run a fitness-themed program that integrates physical activity throughout an extended school day (Education Research Services, 2015). In year two, they expanded to manage grades 5-6 at Spark Academy.

Unlocking Potential (UP), a Boston-based, non-profit middle school turnaround organization, was handed management of the $6^{\text {th }}$ grade at Leonard Middle School in year one (now called UP Leonard). In year two, UP expanded to manage grades 6-8 at UP Leonard and the $6^{\text {th }}$ grade of the Oliver School (now UP Oliver). The Lawrence Teachers Union operated grades 1-5 of the Oliver School (now Oliver Partnership) as of year two.

Additionally, the Phoenix Foundation, a high school charter school provider based in Chelsea, Massachusetts, opened Phoenix Academy--a new alternative high school that targets recent dropouts and students at risk of dropout, including pregnant, parenting, and chronically truant teens. The school aims to provide tailored socio-emotional supports alongside quality academic offerings.

Human Capital. Third was an effort to improve the quality of the District's administrators and teachers. The Receiver took a particularly aggressive approach to improving the quality of school principals and decided that several schools could benefit from new leadership. Specifically, thirty six percent of the principals were replaced in year one and another 20 percent were replaced in year two (Education Research Services, 2015). The national organization Building Excellent Schools offered a year-long training program for school administrators and those staff members determined to have potential to serve as school leaders down the road (Empower Schools, 2014). In year one, the District raised the base salary for new principals to $\$ 105,000$ and for principals with at least three years of experience to $\$ 115,000$ (Education Research Services, 2015).

The Receiver also attempted to improve the quality of the teaching force. Although the Receiver had the authority to require all staff members to reapply for their positions, he did not require them to do so. The District began by identifying a group of about ten percent of all teachers it considered low-performing based on student data, attendance records, and principal reports. Riley then conducted a "Receiver's Review," observing these teachers in the classroom and gathering additional information during the summer of 2012 (Empower Schools, 2014). 
Ultimately, about eight percent of teachers were removed prior to year one of the turnaround. Between the District's dismissals, resignations and retirements, roughly one-third of teachers in 2013 were new to the Lawrence Public Schools (Empower Schools, 2014). The District partnered with Teach for America to assist with recruitment as well as training for current and new teachers (Empower Schools, 2014).

In year two, the District made significant changes to its teacher compensation system. The traditional "steps and lanes" system in which salary was determined based on teacher experience and educational attainment was replaced by a performance-based career ladder system with five major levels: novice, developing, career, advanced and master. Teachers' advancement up the first three rungs of the ladder is based on a teacher's annual end of year evaluation. Advancement to advanced or master status is determined based on the submission of an application that includes evidence of effective teaching such as recommendations from peers and principals, and student growth data for those teaching in tested grades and subjects. The District also instituted a stipend system to support its extending learning time efforts (Lawrence Public Schools, 2013).

The District also created new leadership opportunities for teachers. In year one, LPS established its Teacher Leader Cabinet, providing 100 teachers with a stipend of $\$ 5,000$ to provide the Receiver with guidance on district-wide policy. Additionally, the Sontag Prize was awarded to 168 educators from within and beyond the District. These teachers participated in a professional development weekend at the Harvard Graduate School of Education and received a $\$ 3,000$ stipend to teach at a one-week Acceleration Academy programs (described below).

As a result of changes to the teacher compensation system, in year one of the turnaround, 100 percent of teachers saw a pay increase and 92 percent saw a bump in pay beyond the increase they would have received under the old system (Lawrence Public School, 2013). The average LPS teacher received a $\$ 3,000$ raise for the 2014 school year (Education Research Services, 2015).

Learning Time. The fourth major turnaround component was increased learning time, including expanded school day, enrichment activities, tutoring, and special programs. A non-profit organization, the National Center on Time and Learning, worked with several schools to craft school-level implementation plans for adding hours to the school day. In year one, schools led by outside operators added about 90 minutes to the school day. By year two, the school year was expanded by at least 200 hours for all first through eighth grade students (Empower Schools, 2013). The District also worked to build out after-school enrichment offerings such as theater, dance, arts, music and sports. At the high school level, LPS partnered with Match Education, a non-profit charter school operator and educational program provider, to offer intensive mathematics tutoring to a subset of the $9^{\text {th }}$ and $10^{\text {th }}$ grade students attending two of the District's lowest performing high schools (Education Research Services, 2015).

Acceleration Academies. One particularly notable component of the Receiver's expanded learning time efforts were the "Acceleration Academies." These programs provide struggling students with targeted instruction in either ELA or math, delivered in small groups of ten, by 
select teachers over week-long vacation breaks. ${ }^{5}$ The District's goal is to provide the students who need it most with additional time in front of a talented teacher.

These teachers apply through a competitive process for the Sontag Prize in Urban Education. Selection for the Sontag Prize is based on evaluation ratings and principal recommendations. Teachers were recruited from both within and outside of Lawrence, but the majority of the Academy teachers were Lawrence employees. Participating teachers attend a weekend event at Harvard University which includes an awards dinner, networking opportunities, planning time, team building activities, and professional development delivered by experienced educators, Harvard Graduate School of Education professors, and leaders such as Doug Lemov who discusses techniques from his book Teach Like a Champion. Teachers receive a $\$ 3,000$ honorarium for the week and other giveaways such as branded jackets and iPads.

Principals nominate students from their individual schools to participate in the program. The Central Office makes recommendations about factors principals might consider when selecting students but does not mandate they use any particular criteria. Specifically, the District recommends that principals focus on students in the lowest two categories of proficiency ratings on the previous year's MCAS exams (either the "warning" or "needs improvement" categories). The District also recommends that principals use interim assessment data to identify and nominate students who are not making progress in a particular subject area. The District recommends omitting students with chronic absenteeism (who may be unlikely to attend the Academy) and students with behavioral problems so severe that they would substantially disrupt the learning of others. When pitching the program to parents and students, educators emphasize that the Superintendent has selected them for a special opportunity to get extra academic help. The program is not described as punishment or remediation.

Principals typically use homogenous ability groupings to create classes of ten to twelve students, and teachers are assigned to a single group for the week. Teachers are given substantial flexibility to run classes as they see fit and to create their own lesson plans. Academies held over the February vacation focus on ELA. The April Academies focus primarily on math, but also include some classes dedicated to science. The District asks Academy teachers to focus on frequently assessed MCAS standards and provides a list of these standards, sample objectives, as well as interim assessment data for all of the students in the teacher's class to identify the standards their students have and have not yet mastered.

The daily schedule varies by school, but all students participate from 8am to $3 \mathrm{pm}$. Administrators are told to aim for a total of 25 hours of instruction over the course of the week. Instructional time in the core subject is typically broken up by two "specials" per day, which include subjects such as theater, visual art, music, sports, technology and cooking. Students receive incentives for perfect attendance including $\$ 40$ gift cards and raffle tickets for larger gifts.

Data Use. The fifth and final priority for the turnaround effort was a greater emphasis on the effective use of data. In the first year, The Achievement Network, a national partner

\footnotetext{
${ }^{5}$ In recent years, the District also ran a small handful of classes for higher performing students to provide more advanced targeted instruction than they would get in a typical school day, as well as sections in science.
} 
organization, began working with nine LPS schools to provide training on how to use of data to drive instructional improvement. The Achievement Network helped administer formative assessments and supported schools in using data to target specialized programming for struggling students. In 2014, the Achievement Network expanded to work with a majority of Lawrence schools (Empower Schools, 2014).

\section{METHODS}

Data. We make use of student-level administrative data provided by the Massachusetts Department of Elementary and Secondary Education (MA DESE). The data include students in the state from the 2008 to the 2015 school year, recording information on each student's grade, school, district, demographic characteristics, standardized test scores, attendance and high school graduation status. We supplement the state data with records from LPS on participation in the Acceleration Academies in 2013 and 2014.

Full Sample. Our full sample includes over 500,000 unique students in each year. Our preferred analytic sample includes the roughly one-fourth of students attending the 50 or so school districts in the state in which at least half of the students qualified for free or reduced price lunch as of 2008. Such low-income districts provide a more relevant comparison to LPS, though we show that our findings are generally robust to a number of different sample restrictions that we discuss below.

Outcome Measures. Our primary measures of academic achievement are students' scores on the statewide mathematics and English Language Arts (ELA) MCAS exams, given in $3^{\text {rd }}-8^{\text {th }}$ and $10^{\text {th }}$ grades. We standardize these scores within year, subject and grade using the full sample of Massachusetts students. We also examine additional outcomes including students' school attendance, grade progression, probability of remaining in the same district, probability of remaining enrolled in school, and probability of taking the MCAS in any given year.

Acceleration Academy Participants. LPS' data allows us to identify the students who participated in Acceleration Academies in 2013 and 2014. In 2013, 505 LPS students participated only in a math Acceleration Academy, 570 participated only in an ELA Acceleration Academy, and 495 participated in both types. In total, 1,570 students, or 21 percent of LPS students in tested grades, participated in at least one Acceleration Academy. In 2014, these numbers roughly doubled in each category, so that 42 percent of LPS students participated in at least one Acceleration Academy.

\section{Data-Analytic Plan.}

Modeling Overall Turnaround Effects. To study the overall effect of the turnaround, we conduct difference-in-differences analyses that compare achievement trends of Lawrence students to achievement trends of students in comparable districts that did not experience the turnaround. In all models, we treat the school years 2008-12 as the pre-turnaround control period. We then use two different regression specifications. Model 1, a school-by-grade fixed effects model, is:

$$
Y_{i s g y}=\beta_{0}+\beta_{1} L P S_{i s g y} \times 2013_{y}+\beta_{2} L P S_{i s g y}+\delta_{s g}+\gamma_{g y}+\beta_{3} X_{i s g y}+\varepsilon_{i s g y}
$$


Here, $Y$ is an outcome for student $i$ in school $s$ and grade $g$ in year $y$. LPS is a binary indicator for being enrolled in the Lawrence Public Schools and 2013 indicates the first post-turnaround year. The interaction of these two variables provides an estimate of the extent to which changes in LPS' outcomes in the first year of the turnaround relative to prior years differ from such changes in other comparison districts. We exclude 2014 data in order to focus on first year impacts.

Inclusion of school-by-grade fixed effects $\delta$ implies that estimates are generated by comparing the same school-grade combination to itself over time. Grade-by-year fixed effects control for any statewide shocks common to a given grade in a given year, such as changes in exam difficulty. Student-level demographic controls $X$ account for any compositional changes within LPS or other districts over time. These controls include measures of gender, race, free or reduced price lunch status, English as a second language status, Limited English Proficiency status and special education status. Standard errors are clustered at the school-by-grade level to account for serial correlation in unobserved components of the error term at that level.

We modify this school-by-grade fixed effects model in two important ways. First, in order to account for potential pre-existing differences across schools and districts in student characteristics, we run versions of the model in which we add controls for lagged test score and attendance measures. Specifically, we include math and ELA MCAS scores, as well as the number of days attended as measured one year prior to the outcome being measured. When oneyear lagged scores are missing, we replace them with two-year lags. We refer to this as Model 2, which takes the form:

$$
\begin{aligned}
Y_{i s g y}=\beta_{0} & +\beta_{1} L P S_{i s g y} \times 2013_{y}+\beta_{2} L P S_{i s g y}+\delta_{s g}+\gamma_{g y}+\beta_{3} X_{i s g y} \\
& +E L A_{i s g, y-1}+\text { MATH }_{i s g, y-1}+\text { Attendance }_{i s g, y-1}+\varepsilon_{\text {isgy }}
\end{aligned}
$$

Second, in order to estimate the cumulative effects of the turnaround in 2014, its second year, we run versions of Models 1 and 2 in which we include 2014 data but omit 2013 data and replace 2013 with a 2014 indicator. This allows us to compare the second year of the turnaround to the pre-turnaround period. Including both periods simultaneously would result in estimates of the impact of one year's turnaround conditional on the other year's, causal interpretation of which would be unclear.

Even controlling for school-by-grade fixed effects and lags in student achievement and attendance may not sufficiently account for differential changes over time in the composition of the LPS student population relative to the population in other districts, particularly if such changes occur along unobservable dimensions. To account for this, we run Model 3, a student fixed effects model, of the form:

$$
Y_{i s g y}=\beta_{0}+\beta_{1} L P S_{i s g y} \times 2013_{y}+\beta_{2} L P S_{i s g y}+\delta_{i}+\gamma_{g y}+\varepsilon_{i s g y}
$$

There are only two differences between this model and Models 1 and 2. The main difference is that school-by-grade fixed effects have been replaced by student fixed effects, ensuring that identification of turnaround impacts comes from within-student changes over time. This eliminates compositional changes as a potential source of omitted variable bias. The second and smaller difference is that student fixed effects obviate the need for demographic controls, which 
are constant over time, and lagged measures of achievement, which the model implicitly employs for identification. Here, we cluster standard errors at the student level.

\section{FINDINGS}

\section{Turnaround Impacts on Math and ELA Achievement.}

We begin by using the raw data to explore achievement trends in Lawrence and other districts. Figure 2 illustrates Lawrence's chronic underperformance prior to the receivership. Panel A presents math MCAS scores for all tested Lawrence students and students in other majority lowincome districts in Massachusetts. For the five years leading up to the turnaround, Lawrence students underperformed Massachusetts as a whole by roughly 0.7 standard deviations and underperformed other majority low-income districts by about 0.3 standard deviations. In 2013, the first full year of the turnaround, math scores in Lawrence rose by roughly 0.2 standard deviations relative to the rest of the state, and then rose again by about 0.1 standard deviations in 2014. Math scores in other low-income districts remained relatively flat during this time. This clear break from trend already suggests that the turnaround may have had large impacts on math achievement in Lawrence.

Panel B suggests that in ELA, prior to the turnaround, Lawrence substantially underperformed the rest of the state, by 0.7 standard deviations, and other low-income districts, by 0.2 standard deviations. ELA scores do rise slightly in 2013 and again in 2014 but noisiness of those scores in Lawrence's pre-turnaround period and post-turnaround trends in low-income districts make it less clear whether such increases are due to the turnaround itself.

Table 2 contains estimates generated by our three regression models corresponding to Figure 2 . We focus first on comparisons of LPS to students across the entire state. Estimates from the school-grade fixed effects model suggest that math scores rose by 0.20 standard deviations in the first year of the turnaround and by 0.31 standard deviations by its second year. Inclusion of lagged achievement and attendance measures leaves the first-year estimate nearly unchanged at 0.19 standard deviations but does decrease the estimate of the second year impact to a similar 0.19 standard deviations. The student fixed effects model implies the turnaround improved test scores by 0.12 standard deviations in its first year and by 0.19 standard deviations by its second year.

We confirm that differences in these estimates are driven by the different specifications and not the changing samples across the models. The last three columns of the table show that limiting the sample to other low-income districts has little effect on any of these estimates. We also confirm that these results are not driven by changes in the proportion of students taking these exams. In order to further rule out differential migration as a source of omitted variable bias, we run versions of all of these models in which we fix students' districts as of 2012, regardless of where they subsequently moved. This has no impact on the estimates presented here. Regardless of the model and sample used, all of these estimates suggest that the turnaround had large positive impacts on math achievement. Though Models 2 and 3 differ slightly in their estimates of the first-year impact of the turnaround, both suggest that, by its second year, the turnaround 
had improved LPS students' math scores by a large and statistically significant 0.17-0.19 standard deviations.

In ELA, all three models suggest small first-year impacts, on the order of 0.01-0.02 standard deviations, only one of which is statistically significant. By the second year, the three models suggest slightly larger gains of 0.04-0.09 standard deviations, though only the student fixed effects model suggests a statistically significant impact. Limiting the sample to low-income districts makes the estimates more consistent across specifications. The main takeaway is that the turnaround had no apparent impact on ELA scores in its first year and at best small positive impacts in its second year, on the order of 0.02-0.03 standard deviations.

\section{Turnaround Impacts by Subgroup.}

Because Lawrence has a high proportion of ESL students and because such students traditionally underperform their non-ESL peers, we explore differences in the effect of the turnaround by ESL status. Figure 3 graphs math test scores over time by ESL status. Panel A shows a massive rise in the math scores of Lawrence's ESL students, so much so that they appear to have closed the gap with ESL students in other low-income districts. Panel B shows large math gains for non-ESL students as well, although breaks from prior trends are somewhat less clear. We formalize these estimates in Table 3 by interacting the difference-in-difference specifications in models 2 and 3 with indicators for whether a student speaks English as a second language. Though the subgroup estimates here differ somewhat by the model used, both models confirm that ESL students saw large gains in math in both years of the turnaround. The estimates, as well as panel A of Appendix Figure A, also suggest that ESL students made moderate gains as a result of the turnaround. As panel B of Appendix Figure A shows, non-ESL students appear to have made little progress in ELA. The turnaround is clearly benefitting Lawrence's ESL students, a population of particular concern to the district and to the wider education policy community.

We also explore heterogeneity in turnaround impacts by grade level. Figure 4 graphs math test scores over time by grade level. Panels A and B show large, sharp rises in math scores for Lawrence elementary school and middle school students, so much so that the district has closed the achievement gap with other low-income districts. Panel $\mathrm{C}$ shows some evidence of gains in high school, though not nearly enough to close massive achievement gaps relative to other lowincome districts. Table 4 shows estimates of these impacts using school-by-grade fixed effects Models 1 and $2 .{ }^{6}$ Model 1 's results in the first column match the figures closely, showing gains across all grade levels but particularly large gains in middle school. Controlling for lagged achievement and attendance measures makes the gains appear more evenly distributed across grade levels. Estimated impacts on ELA by grade level, as seen in Appendix Figure B and the last two columns of Table 4, show little clear and consistent heterogeneity.

\section{Acceleration Academies.}

\footnotetext{
${ }^{6}$ Student fixed effects models do not allow us to explore heterogeneity by a fixed grade level, which changes each year for most students.
} 
Acceleration Academies Modeling. To examine possible differences in achievement gains depending on whether Lawrence students participated in an Acceleration Academy, we rely on a modified version of Model 3. The resulting Model 4, a student fixed effects model, is:

$$
\begin{aligned}
& y_{i s g y}=\beta_{0}+\beta_{1} L P S_{i s g y} \times 2013_{y} \times A A M A T H_{i s g y}+\beta_{2} L P S_{i s g y} \times 2013_{y} \times A A E L A_{i s g y} \\
& +\beta_{3} L P S_{i s g y} \times 2013_{y}+\delta_{i}+\gamma_{g y}+E L A_{i s g, y-1}+M_{A T H} H_{i s g, y-1}+\text { Attendance }_{i s g, y-1}+\varepsilon_{i g t}
\end{aligned}
$$

This model includes two three-way interaction terms to indicate whether student $i$ participated in an Acceleration Academy in a particular subject and year. Therefore, $\beta_{1}$ is an estimate of the difference in academic achievement between Lawrence students who were and were not chosen to participate in a math Acceleration Academy in 2013. Here, the interaction between the LPS and 2013 indicators allows us to isolate the effect of the rest of the turnaround bundle in year one. We control for lagged math and ELA test scores as well as lagged attendance given that students were likely selected for Acceleration Academy participation based on their prior academic achievement and attendance record. Again, we exclude 2014 data when estimating the first year effects. We run a separate version of Model 4 in which we include 2014 data but omit 2013 data to compare the second year of Acceleration Academies to the pre-turnaround period. For these 2014 estimates, we replace students' lagged test scores and attendance with their 2012 data to avoid conflating the effects of 2013 and 2014 Academy participation.

Finally, we modify Model 4 to explore the extent to which the achievement differences between Acceleration Academy participants and non-participants persisted beyond the year of the intervention. We refer to this model as Model 5, which takes the following form:

$$
\begin{aligned}
y_{\text {isgy }}=\beta_{0}+ & \beta_{1} L P S_{\text {isgy }} \times 2013_{y} \times A A M A T H_{\text {isgy }}+\beta_{2} L P S_{\text {isgy }} \times 2013_{y} \times A A E L A_{\text {isgy }} \\
& +\beta_{3} L P S_{\text {isgy }} \times 2014_{y}+\delta_{i}+\gamma_{g y}+E_{\text {is }}
\end{aligned}
$$

There are two differences between Model 4 and 5. First, we run Model 5 excluding 2013 data in order to estimate the relationship between 2013 Acceleration Academy participation and 2014 achievement. Second, we replace the interaction between the LPS and 2013 indicators with an interaction between an LPS and 2014 indicator to isolate the 2013 Acceleration Academy effects from the effects of the non-Acceleration Academy components of the turnaround in year two.

Acceleration Academy Findings. We first explore the unadjusted achievement trends for Lawrence Acceleration Academy participants compared to non-participants within and outside of Lawrence. Figure 5 displays MCAS scores for 2013 Academy participants and non-participants, with the LPS part of the sample limited to those in LPS at some point in the post-turnaround period. Panel A illustrates that prior to the Acceleration Academies, participants outperformed non-participants in Lawrence by roughly 0.1 standard deviations. However, participants were still behind other Massachusetts students by about 0.2 standard deviations and their achievement trend leading up to the Academy seems to roughly track that of Lawrence non-participants. ${ }^{7}$ In 2013, the first year of the Acceleration Academies, participants appear to have caught up to, if not surpassed, students in other majority low-income districts in Massachusetts. Specifically, their math scores rose by about 0.3 standard deviations relative to the rest of the state while non-

\footnotetext{
${ }^{7}$ Although participants appear to underperform non-participants in 2008, this is due partly to the fact that relatively few students observed in post-turnaround Acceleration Academies were present in LPS that far back in time.
} 
participants' math scores rose by a smaller, but still substantial 0.2 standard deviations. In 2014, gains appear to continue for both groups, with gains for participants somewhat larger than for non-participants.

Table 5 displays estimates generated by our student fixed effects models. Estimates in the first column suggest that non-participants' 2013 math scores rose by 0.11 standard deviations, whereas Acceleration Academy participants' scores rose by an additional 0.12 standard deviations, for a total first-year improvement of 0.23 standard deviations. The second column suggests that roughly half of the 2013 Acceleration Academy effect faded out by 2014, although overall turnaround effects continued to increase. LPS students who did not participate in the 2013 math Acceleration Academy thus showed substantial gains over the first two years of the turnaround but those who did participate showed even larger gains.

The story is somewhat different for reading achievement. As panel B shows, participants in 2013 ELA Acceleration Academies look generally similar in achievement to non-participants prior to the turnaround. In the first two years of the turnaround, non-participants show little or no gains in ELA achievement, where participants show clear gains that are even larger in 2014. Regression estimates in the third column of Table 5 suggest that non-participants slightly lost ground but this effect is small and somewhat sensitive to the choice of pre-period. ${ }^{8}$ Academy participants gained about 0.09 standard deviations relative to those non-participants, for an overall first-year gain of 0.06 standard deviations. The fourth column suggests these gains for participants largely persisted into 2014.

We note here that our estimates of the effects of the 2013 Acceleration Academies could in theory be biased by differential selection into participation, hence our inclusion of the lagged achievement and attendance variables that LPS administrators described as being part of that selection process. One indication that such controls are sufficient to largely eliminate bias in our estimates is the fact that we observe clear positive impacts of each Acceleration Academy on its own subject but no effects of each Academy on the other subject. If differential selection were an issue here, we would expect to see similar impacts of a given Acceleration Academy across both subjects.

There are two central takeaways from these figures and tables. First, Acceleration Academies appear to have had large positive impacts on achievement in the subjects they focused on. Second, the other components of the LPS turnaround had large positive impacts in math but no impact in ELA. As a result, any positive impacts in ELA appear to be driven largely by Acceleration Academies, whereas improvements in math are generated both by the Academies and by other district initiatives.

We repeat this analysis for the 2014 Acceleration Academies in the bottom panel of Table 5, with corresponding figures in Appendix Figure A. Estimating these impacts is complicated by the fact that 2014 participation status may be correlated with 2013 participation status and other unobservable shocks to students in 2013. We therefore present these estimates but are somewhat

\footnotetext{
${ }^{8}$ When we restrict the pre-period to two years, the 2014 estimate for non-participants becomes marginally significant $(\mathrm{p}=.02)$ and when we restrict the pre-period to a single year, the estimate for non-participants is marginally significant in $2013(\mathrm{p}=.02)$ and not significant in $2014(\mathrm{p}>.05)$.
} 
less confident in their causal interpretation. We present them in part because LPS doubled the number of students participating, so that these estimates provide suggestive evidence about the potential scalability of this intervention.

Participation in the 2014 math Acceleration Academy appears to boost 2014 math scores by 0.18 standard deviations relative to the 0.13 standard deviation gain of non-participants, for an overall gain of 0.32 standard deviations. Participation in the 2014 ELA Acceleration Academy also appears to boost math achievement by an additional 0.06 standard deviations, a small effect that could be spuriously driven by selection bias or could represent true spillovers from the ELA preparation that precedes the math test in time. As such, we find the estimated impacts of the 2014 math Acceleration Academy on math scores to be plausible. Oddly, both math and ELA Acceleration academies appear to boost ELA scores in 2014 by 0.11 standard deviations. Given that ELA testing preceded math Acceleration Academies in time, this suggests that at least some fraction of these estimated effects is driven by selection bias. As such, we put somewhat less stock in these ELA achievement gain estimates.

The bulk of the evidence thus suggests that Acceleration Academies were an important component of LPS' turnaround success. Though selection issues may create some bias in our estimates, results from 2014 are at least suggestive that the positive impacts of Acceleration Academies may be scalable to a wider range of students than LPS selected in its first year of the turnaround.

\section{Turnaround Impacts on Other Academic Outcomes.}

We also look for possible turnaround effects on additional outcomes of interest, but find little evidence of impact. Figure 6 shows the unadjusted days of school attendance by year for Lawrence students compared to students in other majority low-income districts. Interestingly, student attendance shows a large jump in the year prior to the turnaround. However, there is no visual evidence of major differences between Lawrence and comparison districts in the postturnaround period. Nevertheless, we utilize Model 2, our school-by-grade fixed effects model with demographic controls as well as lagged test scores and attendance to estimate the turnaround effect on attendance. In Table 6 we report that Lawrence students under the turnaround appeared to gain between two and three days in school compared to comparison students. However, the Lawrence break from trend in 2012, prior to the turnaround, complicates our ability to interpret this coefficient.

Similarly, in Panel A of Figure 7, we show that overall grade progression in Lawrence does not appear to break from the upward trend in other low-income districts after turnaround implementation. We also examine student mobility. Figure 8 shows that the probability of remaining in the same district was already growing in Lawrence relative to other districts prior to the turnaround, and the magnitude of change in any given year was relatively small (never larger than 0.02 percentage points). We also test for whether the turnaround had an effect on whether a student enrolled in school would remain in school. Figure 9 shows that the probability of remaining enrolled seemed to have increased slightly in the year leading up to the turnaround, both overall and for the high school subsample shown in panel B. In Figure 10 we display the percent of $12^{\text {th }}$ grade students who graduate, conditional on having progressed to $12^{\text {th }}$ grade. 
There does not appear to be visual evidence of a shift in $12^{\text {th }}$ grade graduation in Lawrence over the first two years of the turnaround relative to comparison districts. In sum, we do not find convincing evidence that the turnaround appeared to have a positive or negative effect on any of the alternative academic outcomes we explored.

The one possible exception is grade progression among high school students. Panel B of Figure 8 shows that prior to the turnaround, Lawrence high school students were less likely to progress to the next grade than students in comparison districts, by a magnitude of between ten to 20 percentage points depending on the time point. In the four years leading up to the turnaround, the trend for Lawrence students appears to track the trend for non-Lawrence students. In 2013, the probability that Lawrence high school students progressed to the next grade increased by about eight percentage points while the same figure increased by about two percentage points for comparison students. This probability dipped by about two percentage points for Lawrence students in year two of the turnaround, but they remained about five percentage points more likely to progress than they did in 2012. We report our estimate of the turnaround effect on grade progression with the high school sample in Table 6 . The first year of the turnaround appears to have made Lawrence students about ten percentage points more likely to progress to the next grade. By year two, this effect was reduced slightly to nine percentage points. Therefore, we find suggestive evidence that the turnaround had a statistically significant positive effect on Lawrence high school students' grade progression.

\section{DISCUSSION}

Our findings illustrate that the Lawrence Public Schools receivership has demonstrated promising early results, particularly in terms of students' mathematics achievement and among the district's large ESL population. Students exposed to the first two years of the turnaround appear to have made substantially larger mathematics achievement gains than demographically similar students in other majority low-income school districts across Massachusetts. In ELA, we find some evidence of small positive effects by year two. We find suggestive evidence that the turnaround may have increased the probability that Lawrence high school students progress from one grade to the next and no evidence of slippage on any of the other outcomes we explored.

In both the first and second year of the turnaround, students who participated in Acceleration Academy programs over week-long vacation breaks made larger gains in both ELA and math than did non-participants within and outside of Lawrence. Our estimates of 2013 Academy participation more closely approximate the effect of Academy participation than our 2014 estimates given we find evidence of possible selection effects in year two, particularly for the ELA Academies. In both years, math gains are larger among Academy participants, but the overall math effects cannot be fully explained by Academy participation. Gains in ELA are more fully concentrated among ELA Academy participants.

The magnitude of these effects is notable. In year one, the combined average effect of Acceleration Academy participation, plus the remaining bundle of turnaround reforms was 0.23 standard deviations in math and 0.05 standard deviations in reading. In Table 7, we put these effects into context by comparing them to the size of the effects found in two other studies of related interventions. Here we prefer to rely on the 2013 results given we are less concerned 
about selection effects biasing our Acceleration Academy estimates. If positive selection into the Academies did occur, our estimates of the rest of the turnaround bundle represent a lower bound for the true effect. The combined effects of Acceleration Academy participation plus the rest of the Lawrence turnaround are slightly larger than the effects of injecting high-performing charter school practices into low-performing, traditional public schools in Houston, Texas (Fryer, 2014). Lawrence effects are somewhat smaller than, but still comparable to the effects of grandfathering traditional public school students into charter schools in New Orleans and Boston (Abdulkadiroglu et al., 2014). It is also worth noting that, in contrast to New Orleans, only three percent of Lawrence's 2013 test-takers were in schools and grades taken over by outside operators. Only a small fraction of the widespread achievement gains we observe are attributable to such outside operators.

Based on our year one results alone, the Acceleration Academies seem especially effective, particularly given that they involve only one week of intensive instruction. Although at first glance this may seem like a low-intensity intervention, it is important to keep in mind that participating students receive at least 25 hours of additional instruction in a given subject over the course of the week. The District argues that this adds up to more hours of instruction in a core subject than a student gets in a typical month of school. LPS estimates that this program costs approximately $\$ 800$ per student per week. The bulk of these funds go to teacher stipends, and the remainder pays for teacher professional development, student incentives, and student transportation. These Acceleration Academy programs might be a useful and scalable strategy for schools looking to improve the performance of struggling students in core content areas, regardless of whether or not their districts are pursuing an aggressive district-wide turnaround effort.

Given the large body of research showing that teacher quality accounts for a larger portion of the variation in student achievement than any other school-based factor, and Dee's (2012) finding that California-based School Improvement Grantees that adopted turnaround models compelling the most dramatic staff turnover produced the largest gains, it may be initially surprising that Lawrence achieved large achievement gains while only actively replacing eight percent of the teachers in year one. However, the Acceleration Academies could be thought of, in part, as a human capital intervention since participating students were exposed to teachers selected based on merit.

It is important to keep in mind that our results focus solely on the first two years of the turnaround. The Receiver made additional changes in the 2015 school year including piloting full-day Kindergarten for four-year-olds, implementing a new teacher contract that mandates school-based teacher leadership teams (ERS, 2015), attempting to equalize funding between schools (ERS, 2015), and creating a district-wide family engagement office (LPS, 2013).

Not only is it unclear how these additional changes will impact student achievement in the short run, it is uncertain whether the short-term gains we observe will be sustained over time and translate to longer-term outcomes of interest such as college enrollment and persistence, particularly as the Receivership is phased out and local control of the District is reinstated. Lawrence has made impressive gains, but there is still work to be done to realize the goal of eliminating the gap between Lawrence and Statewide averages. Despite these open questions, 
our study undoubtedly provides an encouraging proof point that the improvement of chronically underperforming districts serving primarily low-income and ESL students is indeed possible. 


\section{References}

Abdulkadiroglu, A., Angrist, J., Hull, P. \& Pathak, P. (2014). Charters without lotteries: Testing takeovers in New Orleans and Boston. National Bureau of Economic Research Working Paper 20792.

Abraham, Y. (2013). A lesson on education from Lawrence. The Boston Globe. (http://www.bostonglobe.com/metro/2013/09/28/lesson-educational-upgrades-fromlawrence/EVHTuj8SwCAS1CDGzQyWFI/story.html).

Angrist, J., Dynarski, S., Kane, T., Pathak, P. \& Walters, C. (2010). American Economic Review, 100(2), 1-5.

Atkinson, J. (2012). Lawrence, MA: City of the Damned. Boston Magazine. (http://www.bostonmagazine.com/2012/02/city-of-the-damned-lawrence-massachusetts/).

Borman, G.D., Hewes, G.M., Overman, L.T. \& Brown, S. (2003). Comprehensive School Reform and Achievement: A Meta-Analysis. Review of Educational Research, Vol. 73, No. 2. (Summer, 2003), pp. 125-230.

Bulkley, K. (2010). Between public and private: Politics, governance, and the new portfolio models for urban school reform. K. Bulkley, J. Henig, and H. Levin (Eds.). Cambridge, MA: Harvard Education Press.

Childress, S., Doyle, D., \& Thomas, D. (2009). Leading for equity: the pursuit of excellence in Montgomery County Public Schools. Cambridge, MA: Harvard Education Press.

Chingos, M., Whitehurst, G., and Gallaher, M. (2015). School Districts and Student Achievement. Education Finance and Policy 10(3): 378-398.

Chrispeels, Burke, Johnson, \& Daly (2008). Aligning mental models of district and school leadership teams for reform coherence. Education and Urban Society. 40, 730-750.

Dee, T. (2012). School Turnarounds: Evidence from the 2009 Stimulus. Program on Education Policy and Governance Working Papers Series. Retrieved from: http://www.hks.harvard.edu/pepg/PDF/Papers/PEPG12-04_Dee.pdf

Dobbie, W. \& Fryer, R. (2011). Are high quality schools enough to increase achievement among the poor? Evidence from the Harlem Children's Zone. American Economic Journal: Applied Economics, 3(2011), pp. 158-187.

Education Research Services (2015). Back from the brink: Lawrence, Massachusetts. School System 20/20 Case Study. http://www.erstrategies.org/library/lawrence_public_schools_case_study 
Empower Schools (2014). Urban school reform in Lawrence Massachusetts: Pioneering the "open architecture" model. ( http://empowerschools.org/lawrence-case-study/).

Fryer, R. (2014). Injecting charter school best practices into traditional public schools: Evidence from field experiments. Quarterly Journal of Economics. doi: 10.1093/qje/qju011

Fullan, M. (2007). The new meaning of educational change. New York, NY: Teachers College Press.

Gewertz, C. (2009). Duncan's call for school turnarounds sparks debate. Education Week, 28(37).

Gill, B., Zimmer, R., Christman, J., \& Blanc, S. (2007). State Takeover, School Restructuring, Private Management, and Student Achievement in Philadelphia. RAND Corporation.

Harris, D. \& Larsen, M. (2016). The Effects of the New Orleans School Reforms on Student Outcomes. Working Paper. Tulane University, Education Research Alliance for New Orleans. New Orleans, LA.

Honig, M. (2013). From tinkering to transformation: Strengthening school district central office performance. Education Outlook. American Enterprise Institute for Public Policy Research.

Honig, M. \& Hatch, T. (2004). Crafting coherence: How schools strategically manage multiple, external demands. Educational Researcher, 33(16).

Johnson, S.M., Marietta, G., Higgins, M., Mapp, K. \& Grossman, A. (2015). Achieving coherence in district improvement: Managing the relationship between the central office and schools. Cambridge, MA: Harvard Education Press.

Jonas, M. (2012). High stakes test: Trying to fix a broken school district may be the right thing to do, but no one has ever succeeded at it. Can Lawrence break the mold? Commonwealth Magazine. (http://www.commonwealthmagazine.org/News-andFeatures/Features/2012/Fall/003-High-stakes-test.aspx).

Junge, C. (2014). A school on the move-literally. Ed. Magazine. (http://www.gse.harvard.edu/news-impact/2014/01/a-school-on-the-move-literally/).

Kraft, M (2015). How to Make Additional Time Matter: Integrating Individualized Tutorials into an Extended Day. Education Finance and Policy, 10(1), 81-116.

Lawrence Public Schools (2014). LPS Turnaround. (http://www.lawrence.k12.ma.us/aboutlps/lps-turnaround).

Lawrence Public Schools (2013). Professional compensation system. https://vimeo.com/63110985 
Levin, B. (2008). How to change 5,000 schools: A practical approach for leading change at every level. Cambridge, MA: Harvard Education Press.

Massachusetts Department of Elementary and Secondary Education (2012). Lawrence Public Schools Turnaround Plan. Retrieved from:

http://www.doe.mass.edu/apa/sss/turnaround/level5/LawrencePlan.pdf

Massachusetts Department of Elementary and Secondary Education (2013). Accountability, Partnership, \& Assistance. (http://www.doe.mass.edu/apa/sss/turnaround/default.html).

Massachusetts Department of Elementary and Secondary Education (2015). Lawrence: Total Expenditure Per Pupil, All Funds, By Function.

http://profiles.doe.mass.edu/profiles/finance. aspx orgcode $=01490000 \&$ orgtypecode $=5 \&$

Papay, J. (2015). The Effects of School Turnaround Strategies in Massachusetts. Working Paper.

Riley, J. (2013). Lawrence Public Schools Receivership: The Open Architecture Model. Presentation to the Boston Foundation. (https://www.youtube.com/watch?v=rkGFIzfYZ0w).

Smarick, A. (2010). Toothless reform. Education Next, 10(2), pp. 15-22.

Strunk, K. O., Marsh, J. A., Hashim, A., Bush, S., \& Weinstein, T. (2012). The Efficacy of the Los Angeles Unified School District Public School Choice Initiative for Student Achievement Outcomes: Early Evidence from the First Year. Working Paper.

Supovitz, J. (2006). The case for district-based reform: Leading, building and sustaining school improvement. Cambridge, MA: Harvard Education Press.

U.S. Census (2015). State and county quickfacts: Lawrence (city), Massachusetts. http://quickfacts.census.gov/qfd/states/25/2534550.html

U.S. Department of Education (2012). Turning around the lowest-performing schools. http://www2.ed.gov/policy/elsec/guid/esea-flexibility/resources/turn-around.pdf

Vogler, M. (2012). College hopes renewed for Lawrence dropouts. Eagle Tribune. (http://www.eagletribune.com/latestnews/x2068761871/College-hopes-renewed-for-Lawrencedropouts/print).

Vogler, M. (2013). Riley's reflections. Eagle Tribune.

(http://www.eagletribune.com/local/x730427690/RILEYS-REFLECTIONS/print).

Wong, K. \& Shen, F. (2009). City and state takeover as a school reform strategy. ERIC Digest, $174,2-4$. 
Wong, K. \& Shen, F. (2009). Measuring the effectiveness of city and state takeover as a school reform strategy. Peabody Journal of Education, 78(4), 89-119.

Wong, K. \& Shen, F. (2002). Politics of state-led reform in education: market competition and electoral dynamics. Educational Policy, 16: 161.

Zavadsky, H. (2012). School turnarounds: The essential role of districts. Cambridge, MA: Harvard Education Press.

Zavadsky, H. (2013). Scaling turnaround: A district improvement approach. Washington, D.C.: American Enterprise Institute. Retrieved from: http://www.aei.org/outlook/education/k12/system-reform/scaling-turnaround-a-district-improvement-approach/ 


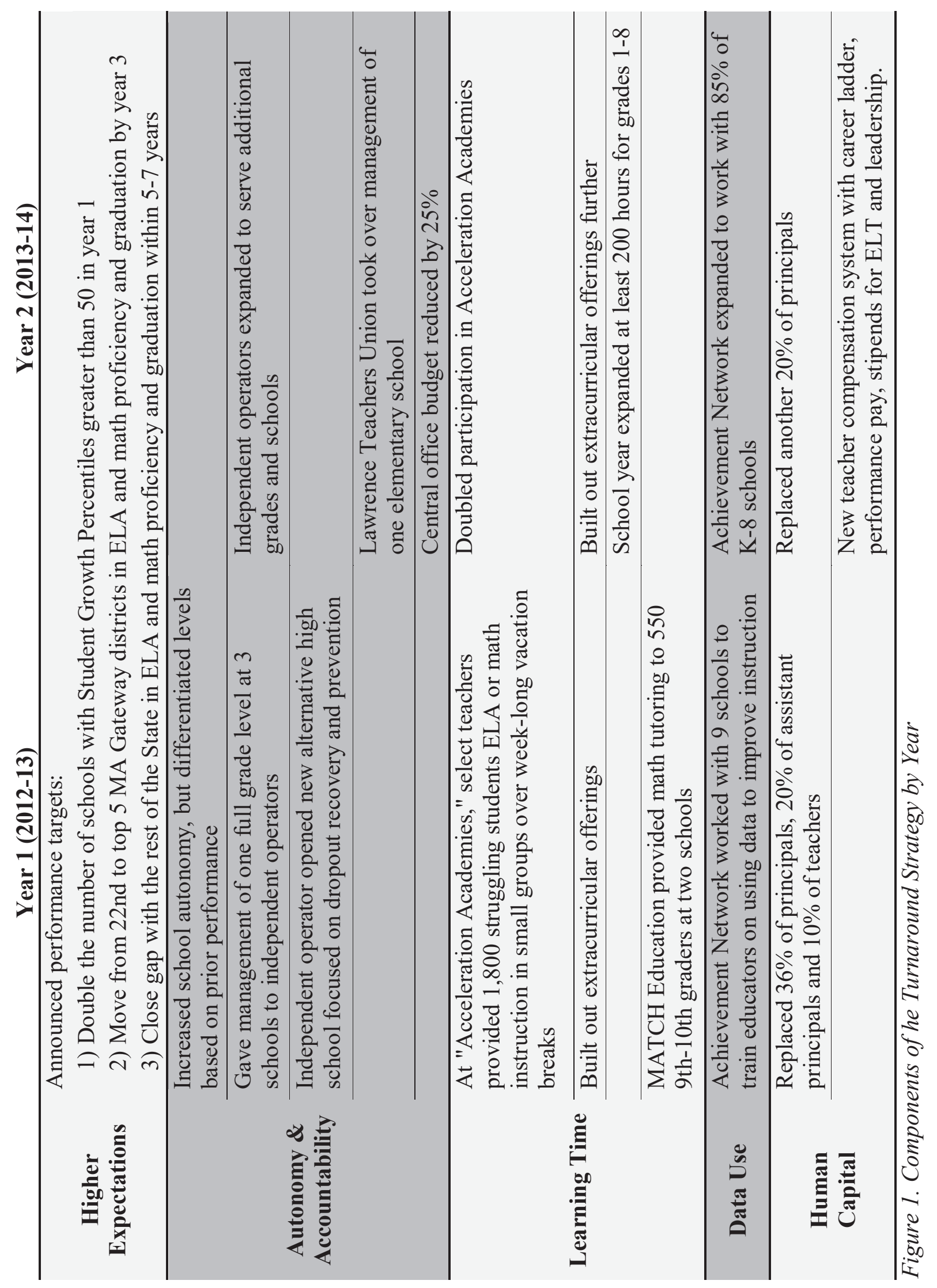




\begin{tabular}{|c|c|c|c|c|c|c|}
\hline & \multicolumn{3}{|c|}{ Pre-Receivership (2008-2012) } & \multicolumn{3}{|c|}{ Post-Receivership (2013-2014) } \\
\hline & Lawrence & $\begin{array}{l}\text { Rest of } \\
\text { MA }\end{array}$ & $\begin{array}{c}\text { Low- } \\
\text { income }\end{array}$ & Lawrence & $\begin{array}{c}\text { Rest of } \\
\text { MA }\end{array}$ & $\begin{array}{c}\text { Low- } \\
\text { income }\end{array}$ \\
\hline Female & .47 & .49 & .48 & .47 & .49 & .48 \\
\hline FRPL & .90 & .33 & .75 & .92 & .37 & .78 \\
\hline White & .07 & .70 & .31 & .06 & .67 & .28 \\
\hline Black & .02 & .09 & .22 & .02 & .09 & .22 \\
\hline Hispanic & .89 & .13 & .34 & .89 & .15 & .37 \\
\hline Asian & .02 & .05 & .07 & .02 & .06 & .07 \\
\hline Other & .01 & .03 & .05 & .02 & .04 & .06 \\
\hline ESL & .82 & .17 & .40 & .77 & .19 & .43 \\
\hline LEP & .38 & .10 & .24 & .50 & .13 & .31 \\
\hline SPED & .26 & .24 & .26 & .24 & .24 & .25 \\
\hline $\begin{array}{l}\text { ELA Score } \\
\text { Math }\end{array}$ & -.74 & .01 & -.52 & -.72 & .01 & -.49 \\
\hline Score & -.76 & .02 & -.47 & -.51 & .01 & -.43 \\
\hline $\begin{array}{l}\mathrm{N} \text { of } \\
\text { students }\end{array}$ & 20,777 & $1,279,546$ & 361,546 & 14,975 & 979,091 & 266,072 \\
\hline $\begin{array}{l}\mathrm{N} \text { of } \\
\text { districts }\end{array}$ & 1 & 405 & 59 & 1 & 409 & 56 \\
\hline
\end{tabular}

Note: All cells represent averages over multiple years. Demographic indicators are constant within student over time. The low-income sample includes students in districts outside of Lawrence that were majority low-income in 2008. 


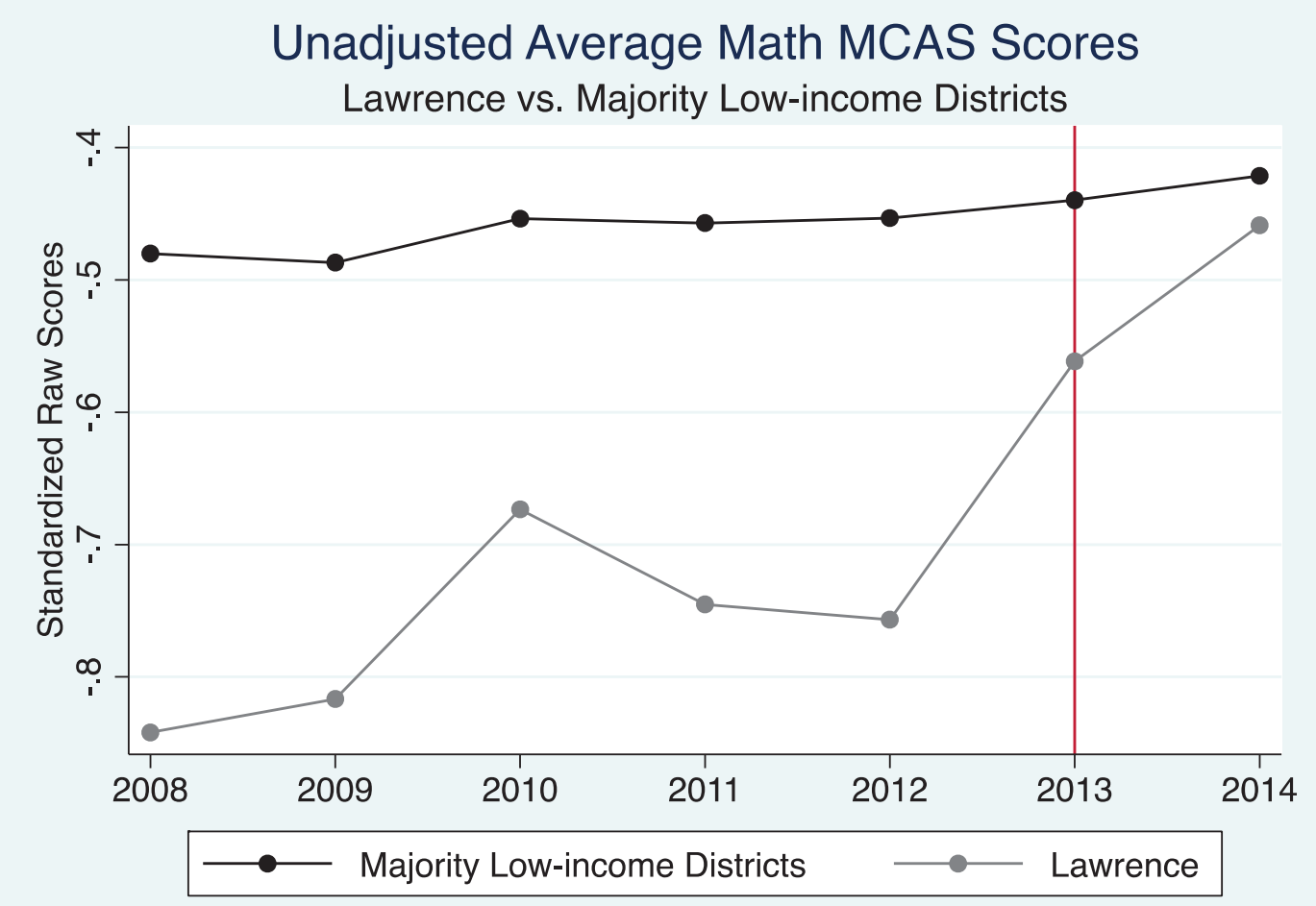

Unadjusted Average ELA MCAS Scores

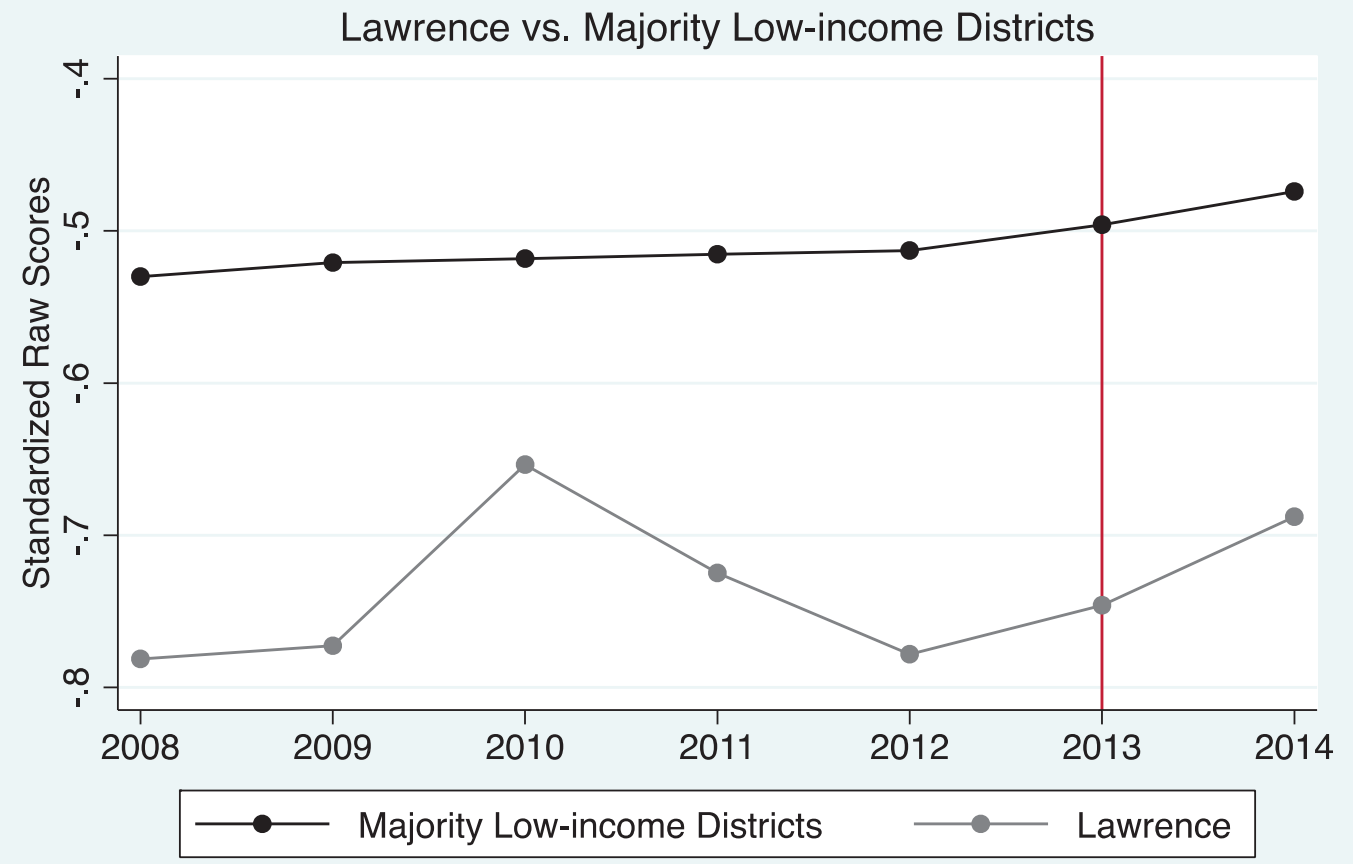

Figure 2. Overall Mean Math and ELA MCAS Scores 


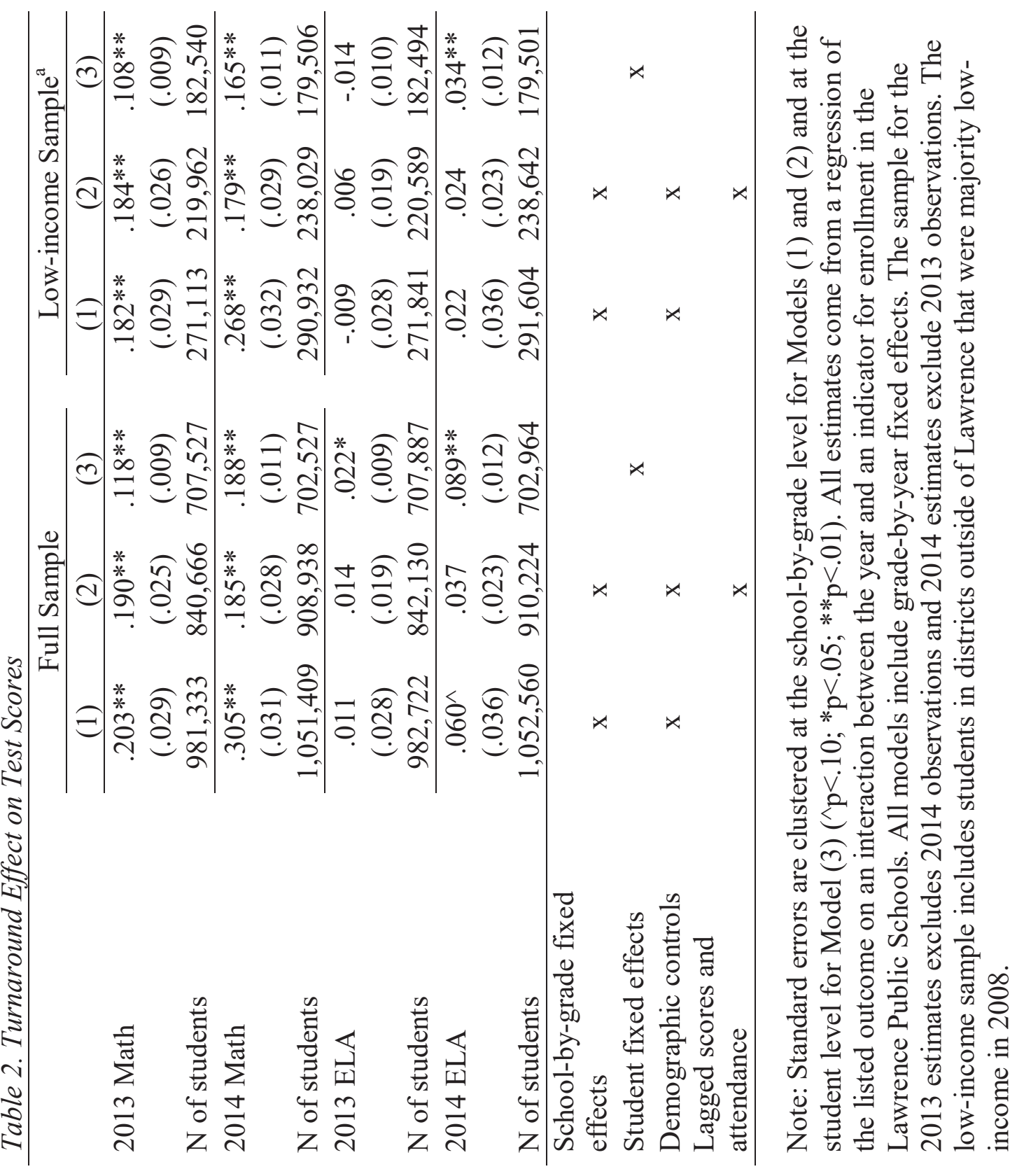



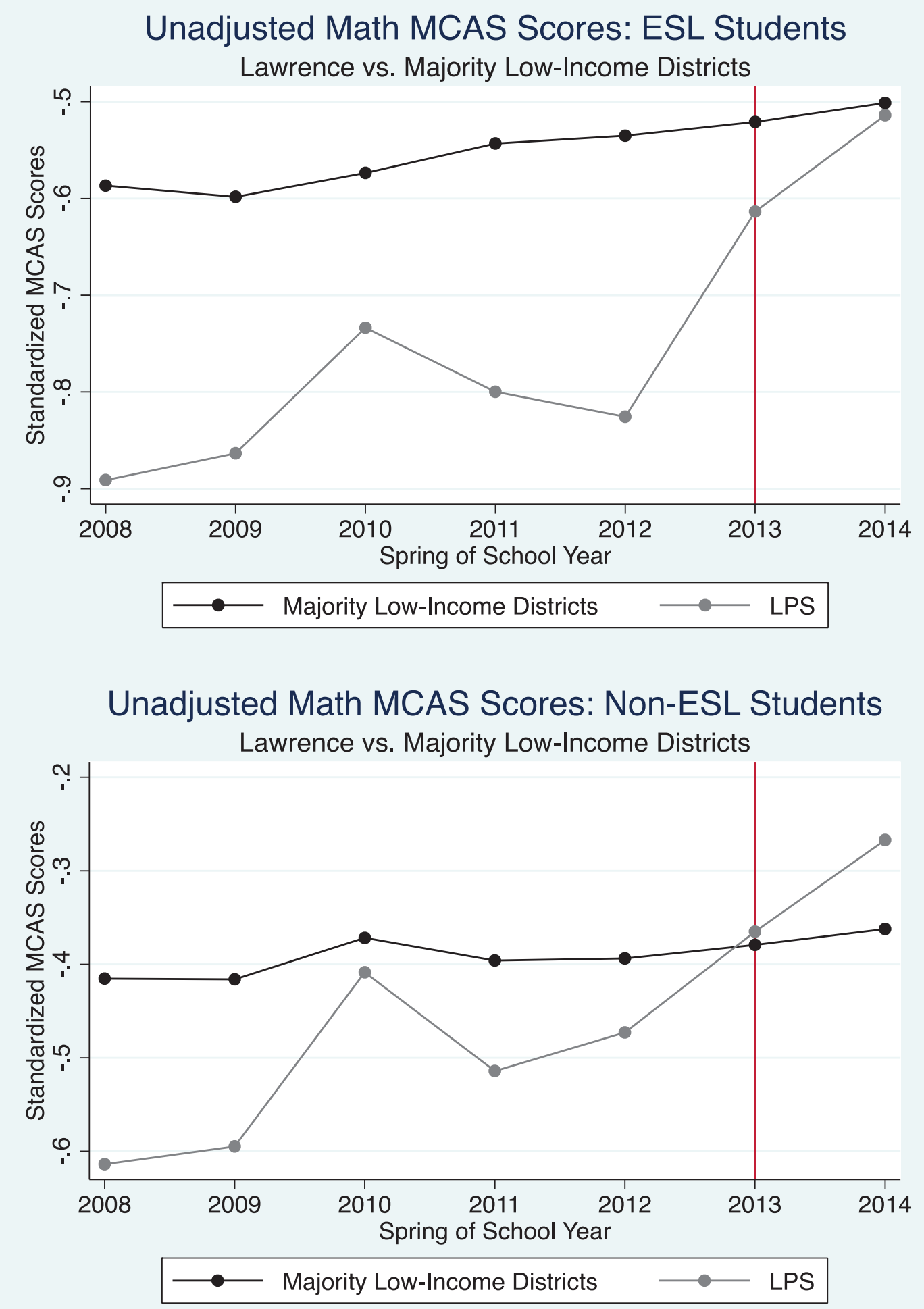

Figure 3. Mean Math MCAS Scores by ESL Status 

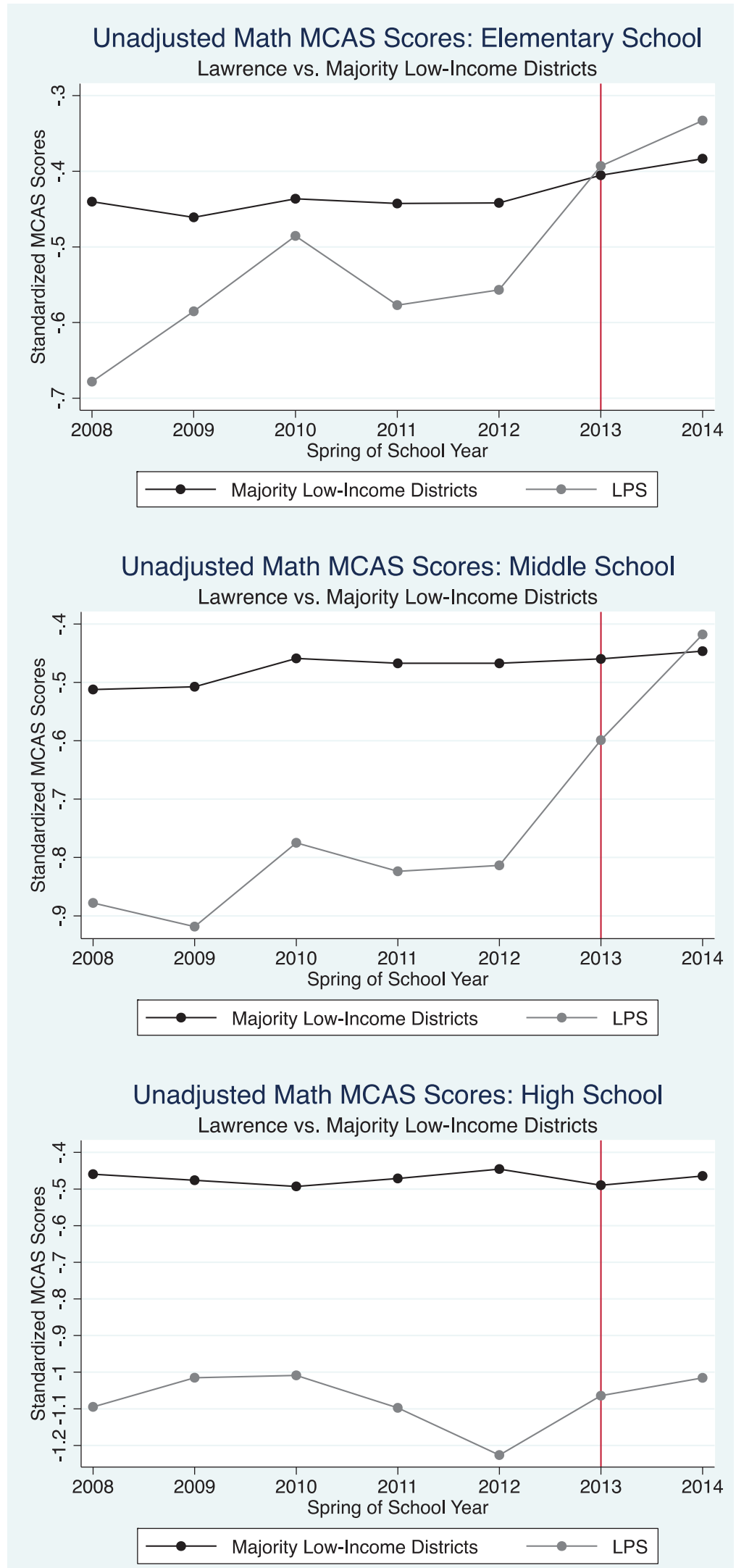

Figure 4. Mean Math MCAS Scores by Grade Level 
Table 3. Turnaround Effect on Test Scores, by ESL Status

\begin{tabular}{|c|c|c|c|c|}
\hline \multirow{2}{*}{ 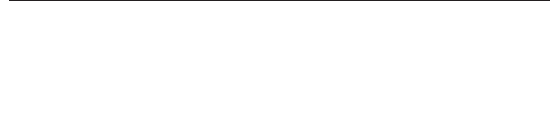 } & \multicolumn{2}{|c|}{ Math } & \multicolumn{2}{|c|}{ ELA } \\
\hline & (1) & (2) & (1) & (2) \\
\hline \multirow{2}{*}{2013 Non-ESL } & $.154 * *$ & .026 & -.017 & $-.102 * *$ \\
\hline & $(.028)$ & (.019) & $(.027)$ & $(.019)$ \\
\hline \multirow[t]{2}{*}{2013 ESL } & $.191 * *$ & $.127 * *$ & .011 & .008 \\
\hline & $(.027)$ & $(.010)$ & $(.019)$ & $(.011)$ \\
\hline $\mathrm{N}$ of students & 219,962 & 182,540 & 220,589 & 182,494 \\
\hline 2014 Non-ESL & $.153 * *$ & .033 & -.031 & $-.101 * *$ \\
\hline \multirow{2}{*}{2014 ESL } & $\begin{array}{l}(.031) \\
.187 * *\end{array}$ & $\begin{array}{l}(.022) \\
.198^{* *}\end{array}$ & $\begin{array}{l}(.031) \\
.041^{\wedge}\end{array}$ & $\begin{array}{l}(.025) \\
.067 * *\end{array}$ \\
\hline & $(.030)$ & $(.012)$ & $(.023)$ & $(.014)$ \\
\hline $\mathrm{N}$ of students & 238,029 & 179,506 & 238,642 & 179,501 \\
\hline School-by-grade fixed effects & $\mathrm{x}$ & & $\mathrm{x}$ & \\
\hline Student fixed effects & & $\mathrm{x}$ & & $\mathrm{x}$ \\
\hline Demographic controls & $\mathrm{x}$ & & $\mathrm{x}$ & \\
\hline Lagged scores and attendance & $\mathrm{x}$ & & $\mathrm{x}$ & \\
\hline
\end{tabular}

Note: Standard errors are clustered at the school-by-grade level for Model (1) and at the student level for Model (2) $\left({ }^{\wedge} \mathrm{p}<.10 ; * \mathrm{p}<.05 ; * * \mathrm{p}<.01\right)$. All estimates come from a regression of the listed outcome on two three-way interactions between the year, an indicator for enrollment in the Lawrence Public Schools, and an indicator for ESL status. All models include gradeby-year fixed effects. The sample for the 2013 estimates excludes 2014 observations and 2014 estimates exclude 2013 observations. All samples include only students in districts outside of Lawrence that were majority low-income in 2008. 
Table 4. Turnaround Effect on Test Scores, by Grade Level

\begin{tabular}{|c|c|c|c|c|}
\hline & $\mathrm{M}$ & & & $\mathrm{A}$ \\
\hline & (1) & (2) & (1) & (2) \\
\hline 2013 Elementary & $.129^{* *}$ & $.163 * *$ & -.055 & -.024 \\
\hline & $(.044)$ & $(.036)$ & $(.035)$ & $(.032)$ \\
\hline 2013 Middle & $.251^{* *}$ & $.184 * *$ & .062 & .008 \\
\hline & $(.041)$ & $(.038)$ & $(.039)$ & $(.024)$ \\
\hline 2013 High & .113 & $.247 * *$ & -.110 & $.093 *$ \\
\hline & $(.073)$ & $(.077)$ & $(.129)$ & $(.045)$ \\
\hline $\mathrm{N}$ of students & 271,113 & 219,962 & 271,841 & 220,589 \\
\hline 2014 Elementary & $.141^{* *}$ & $.077^{\wedge}$ & $-.082^{\wedge}$ & -.002 \\
\hline & $(.041)$ & $(.044)$ & $(.047)$ & $(.046)$ \\
\hline 2014 Middle & $.421^{* *}$ & $.236^{* *}$ & $.146^{* *}$ & .037 \\
\hline & $(.034)$ & $(.034)$ & $(.033)$ & $(.030)$ \\
\hline 2014 High & $.180^{*}$ & $.198^{\wedge}$ & -.047 & .039 \\
\hline & $(.079)$ & $(.096)$ & $(.153)$ & $(.041)$ \\
\hline $\mathrm{N}$ of students & 290,932 & 238,029 & 291,604 & 238,642 \\
\hline Lagged scores and attendance & & $\mathrm{x}$ & & $\mathrm{x}$ \\
\hline
\end{tabular}

Note: Standard errors are clustered at the school-by-grade level $\left({ }^{\wedge} \mathrm{p}<.10\right.$; $* \mathrm{p}<.05 ; * * \mathrm{p}<.01)$. All estimates come from a regression of the listed outcome on three three-way interactions between the year, an indicator for enrollment in the Lawrence Public Schools, and an indicator for grade level $($ Elementary $=$ grade $<6$; Middle $=$ grades $6-8 ; \mathrm{High}=$ grade 10$)$. All models include demographic controls, school-by-grade fixed effects, and grade-byyear fixed effects. The sample for the 2013 estimates excludes 2014 observations and 2014 estimates exclude 2013 observations. All samples include only students in districts outside of Lawrence that were majority low-income in 2008. 


\section{Acceleration Academies}

\section{Unadjusted Math MCAS}

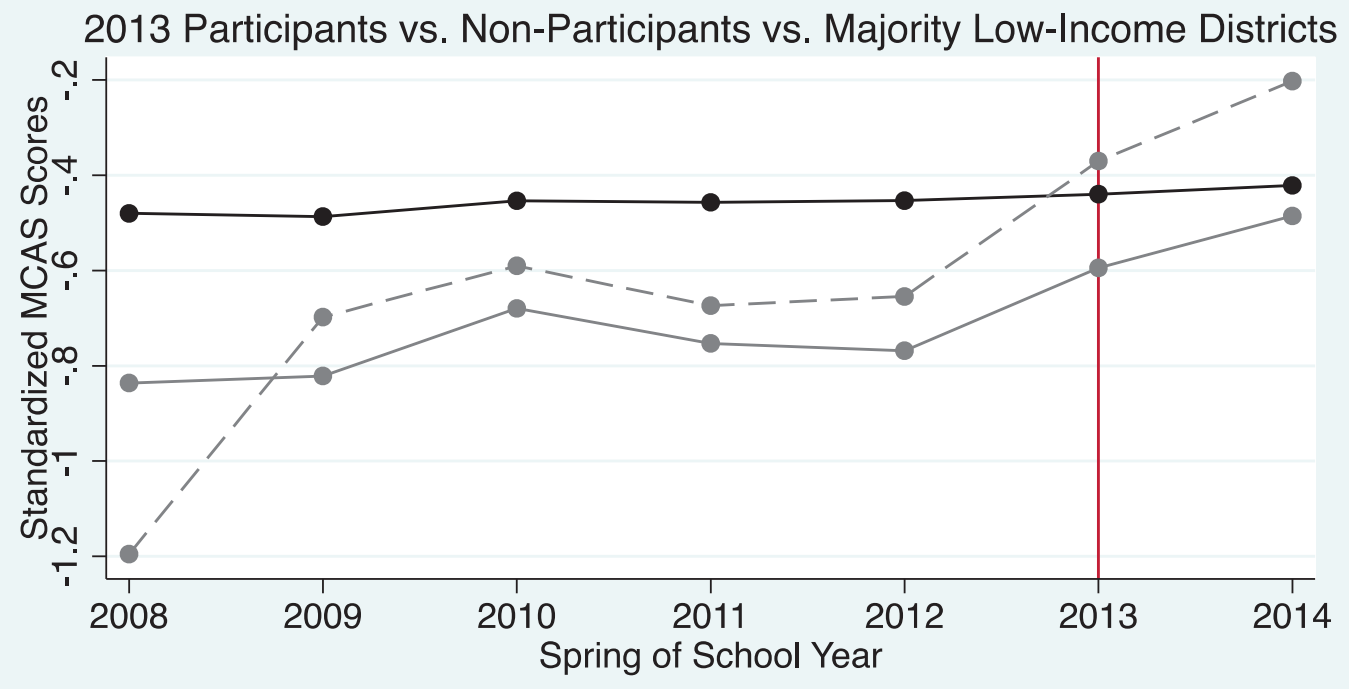

$\longrightarrow$ Majority Low-Income Districts —— LPS Non-Participants

$-\rightarrow-$ LPS AA Participants

\section{Unadjusted ELA MCAS}

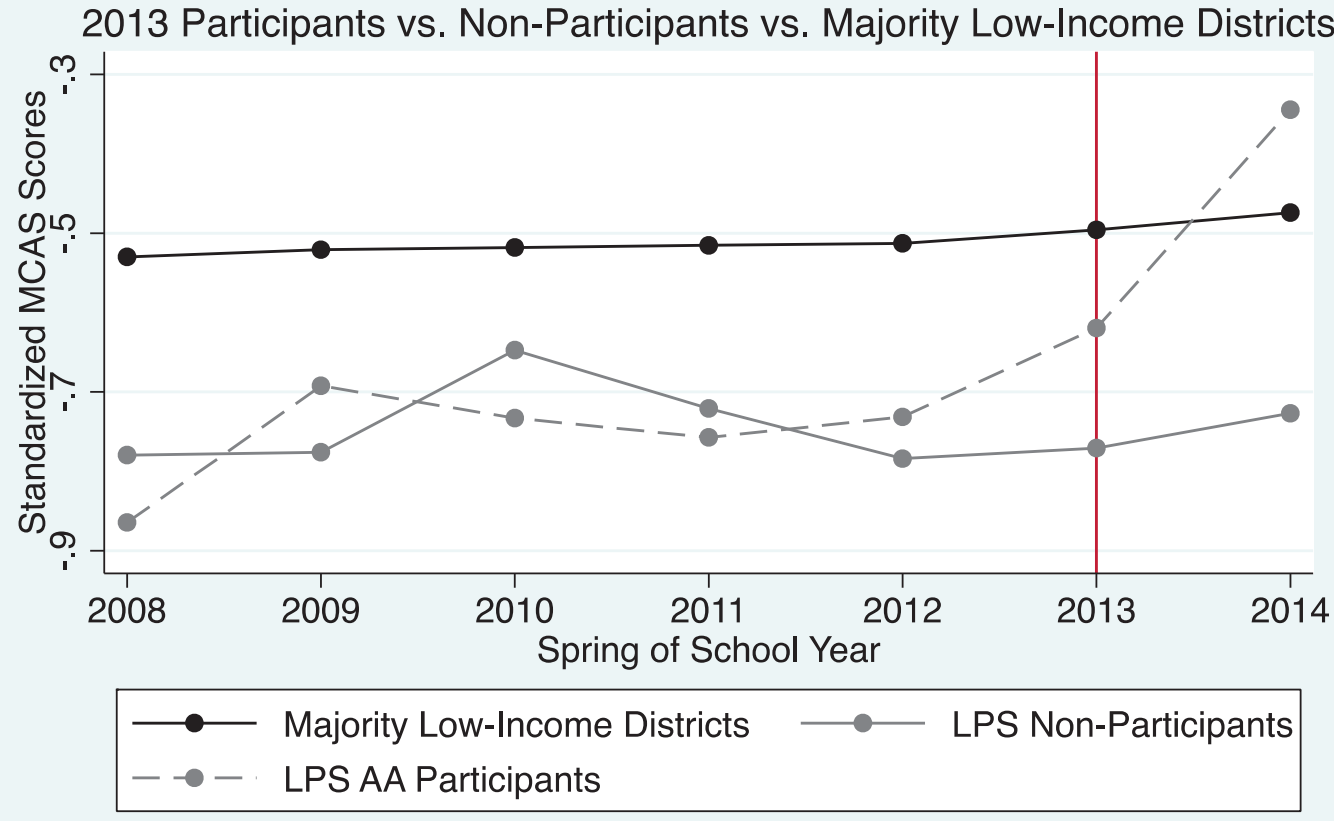

Figure 5. Mean MCAS Scores by 2013 Acceleration Academy Participation 


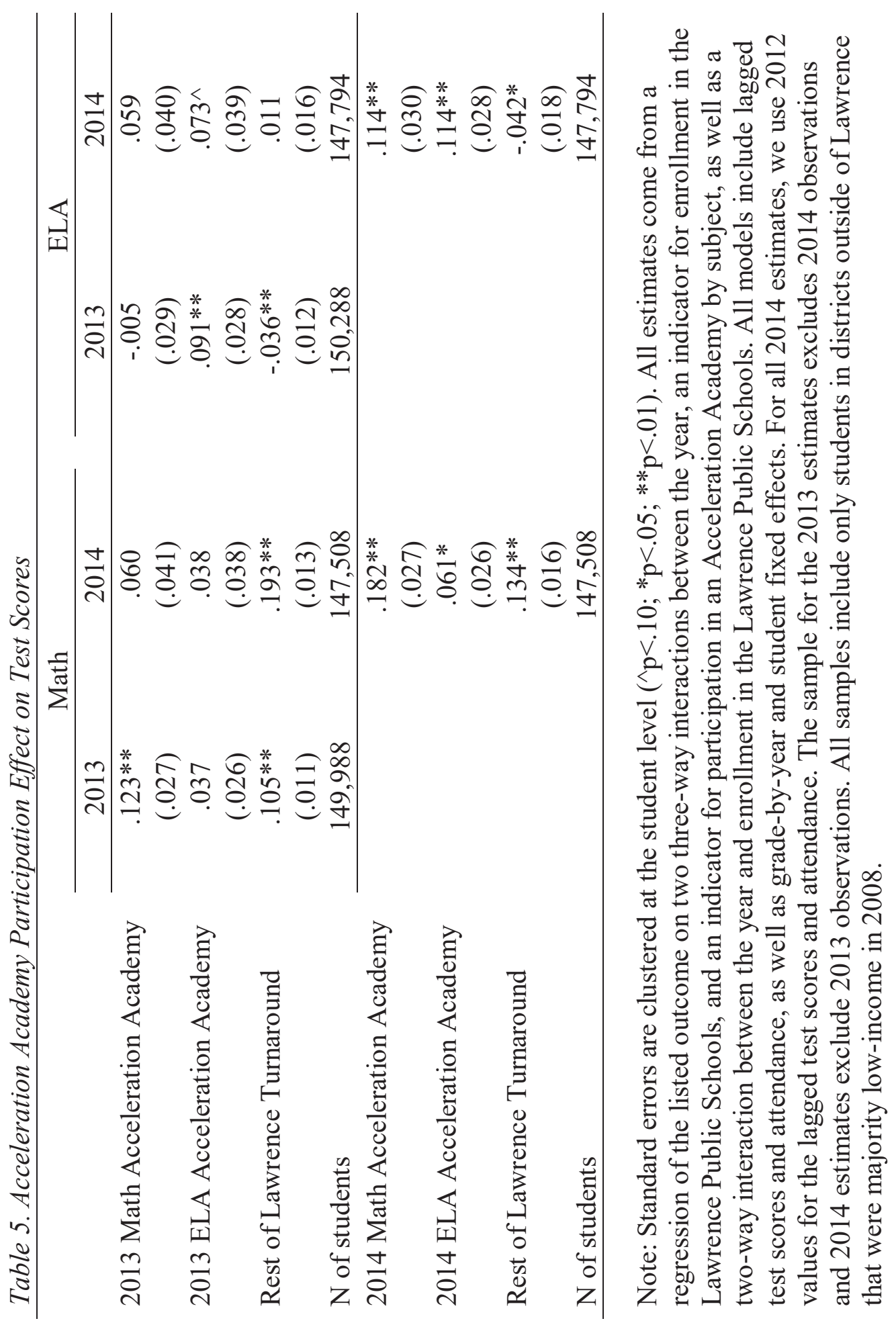




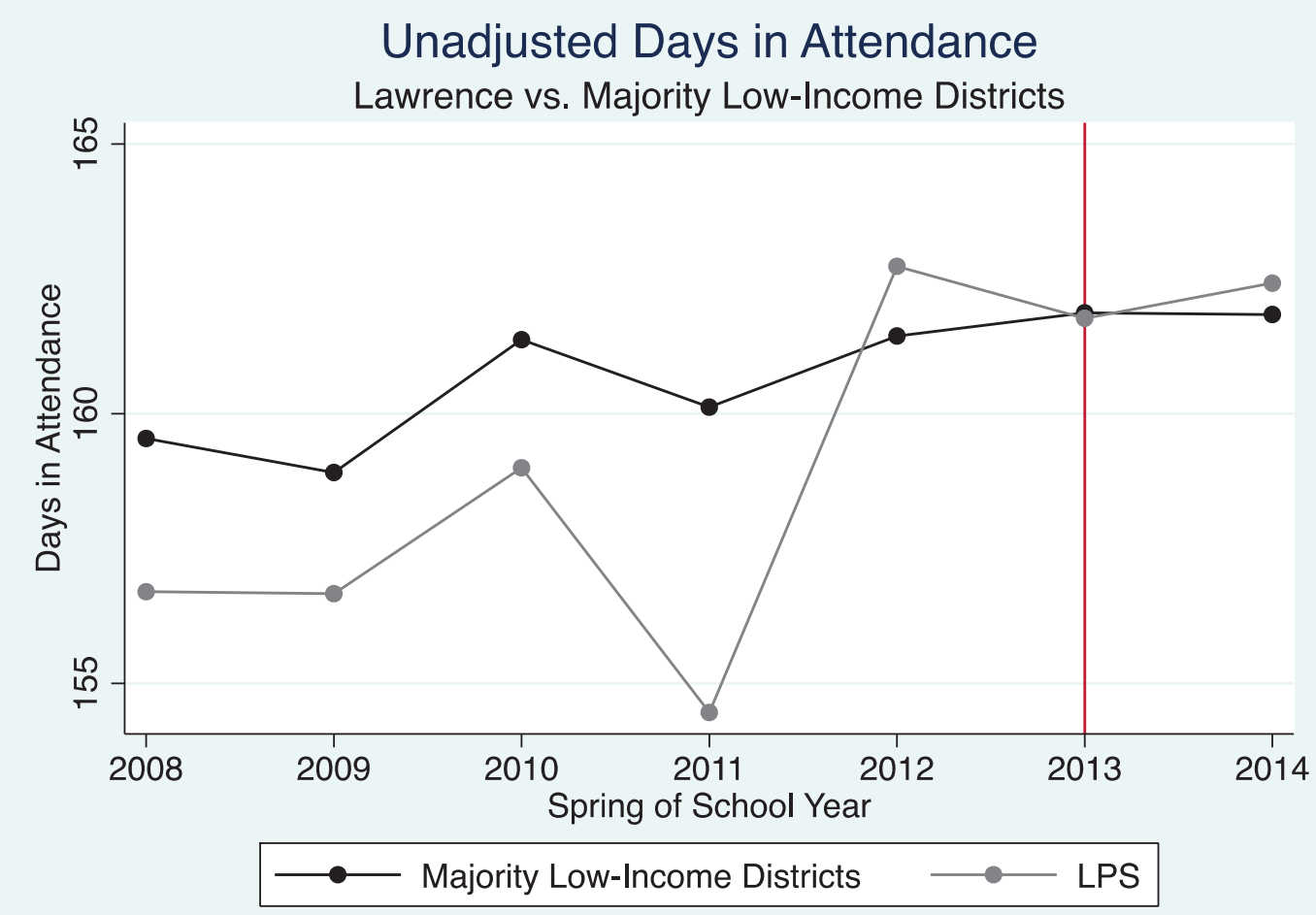

Figure 6. Overall Mean Days in Attendance 


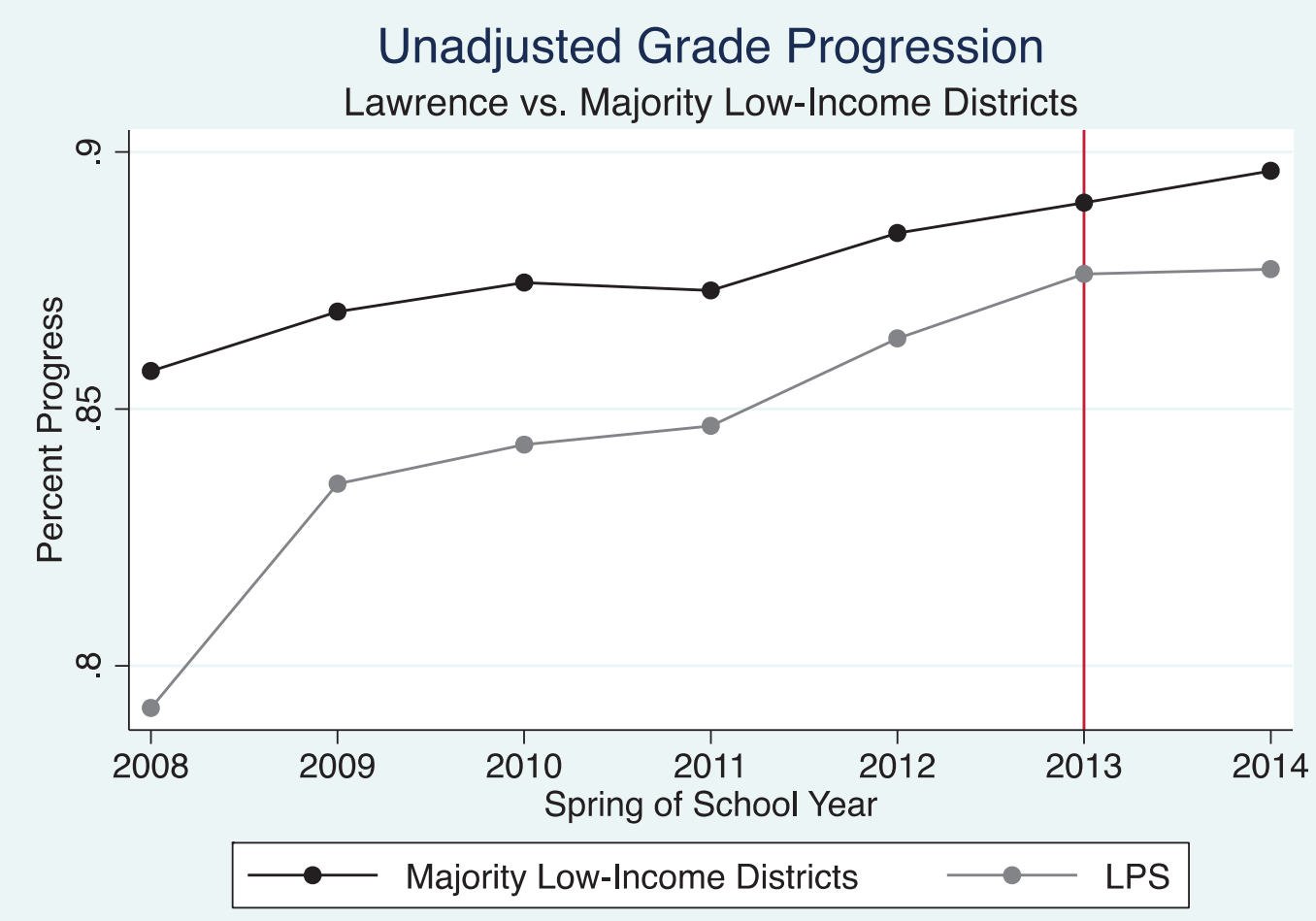

\section{Unadjusted Grade Progression: High School} Lawrence vs. Majority Low-Income Districts

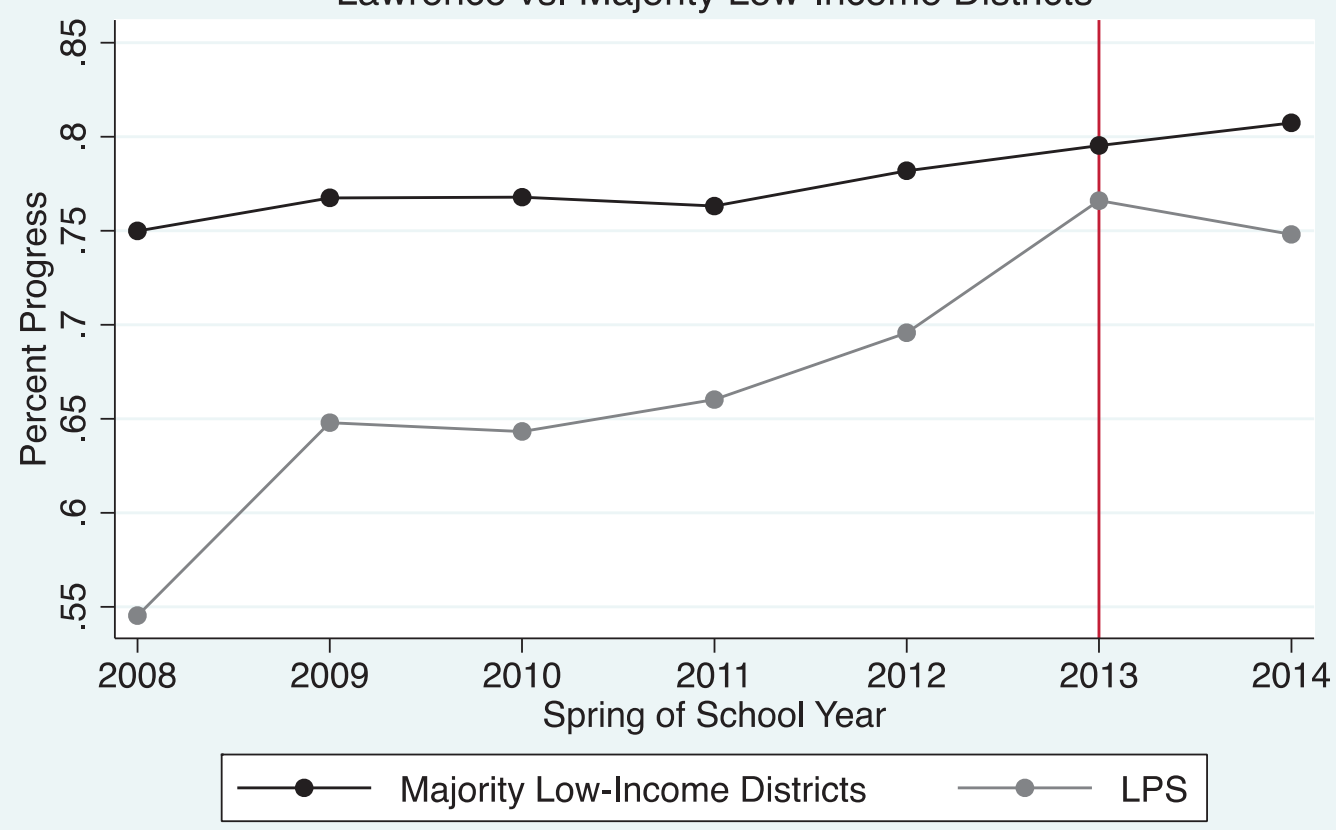

Figure 7. Percent of Students Making Grade Progress, Overall and Among High School Students 


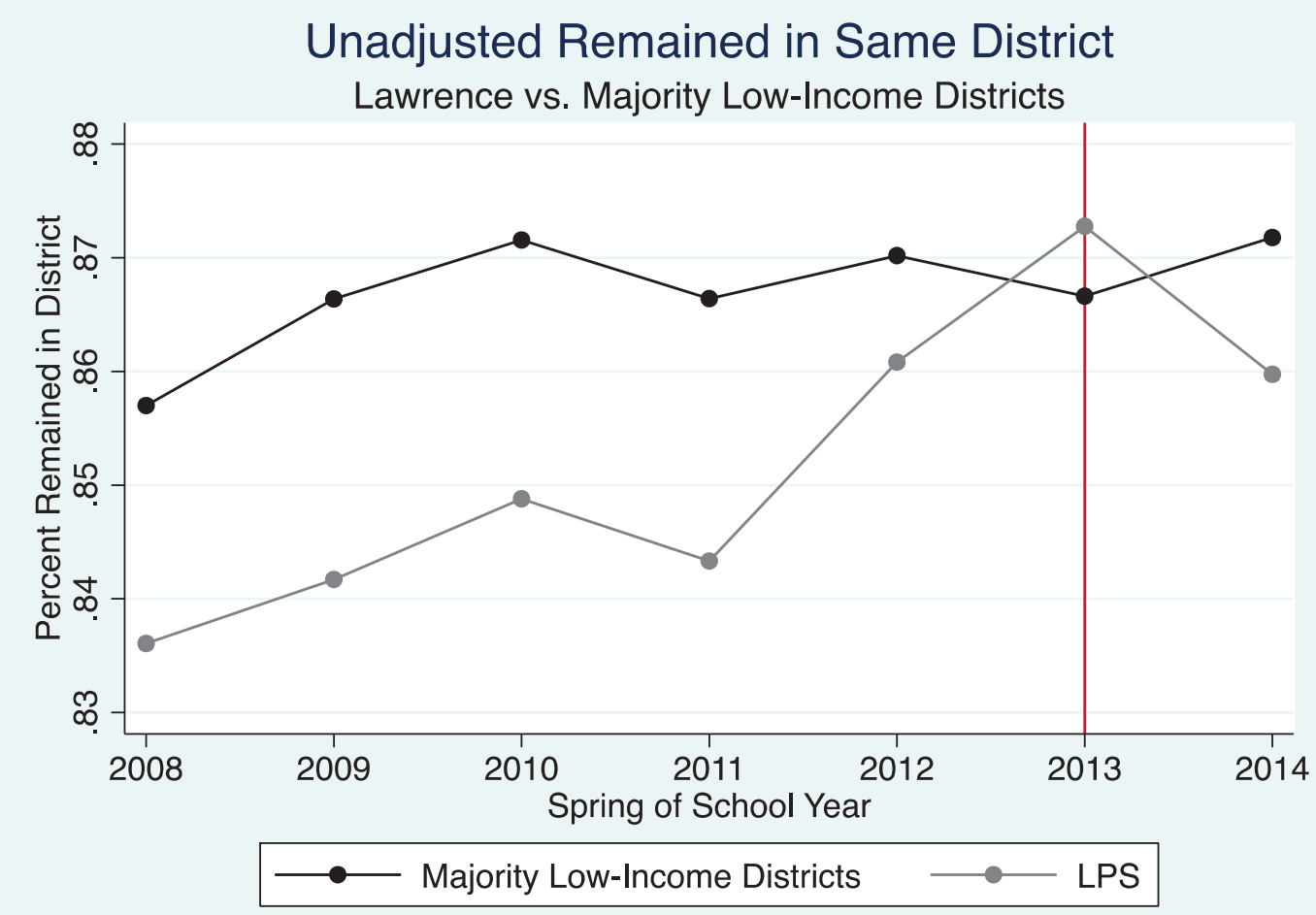

Figure 8. Overall Percent of Students Remaining in the Same District 


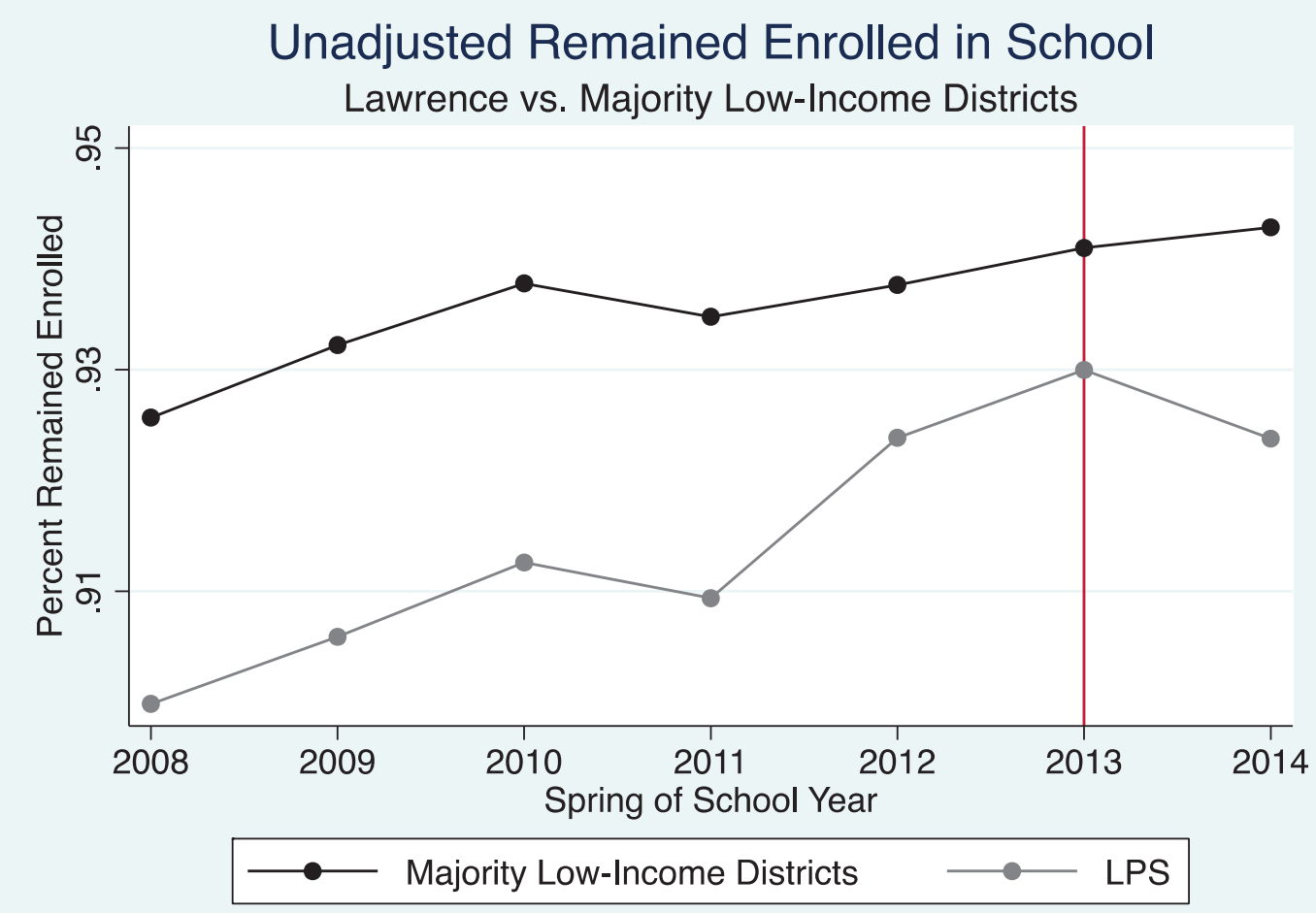

Unadjusted Remained Enrolled: High School

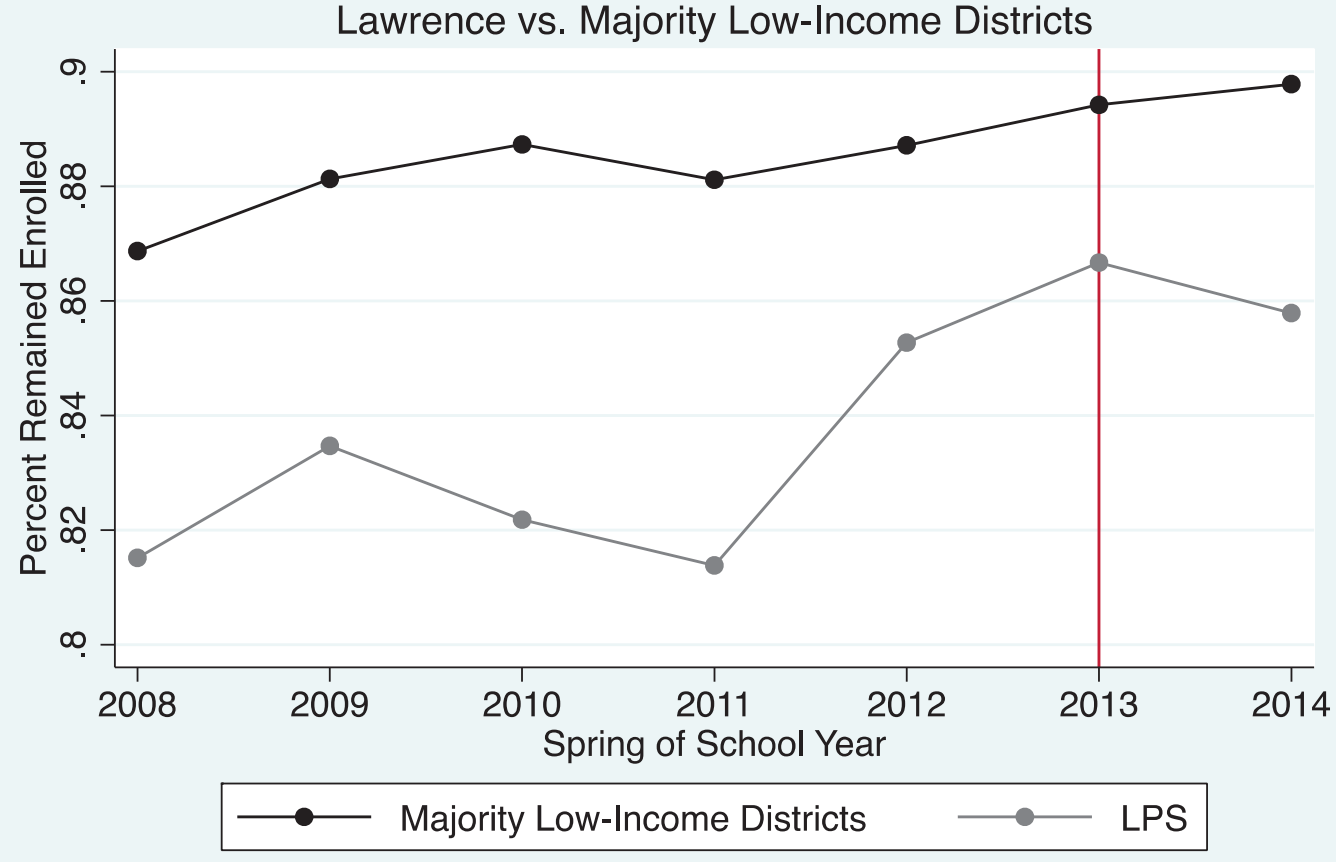

Figure 9. Overall Percent of Students Remaining Enrolled in School 


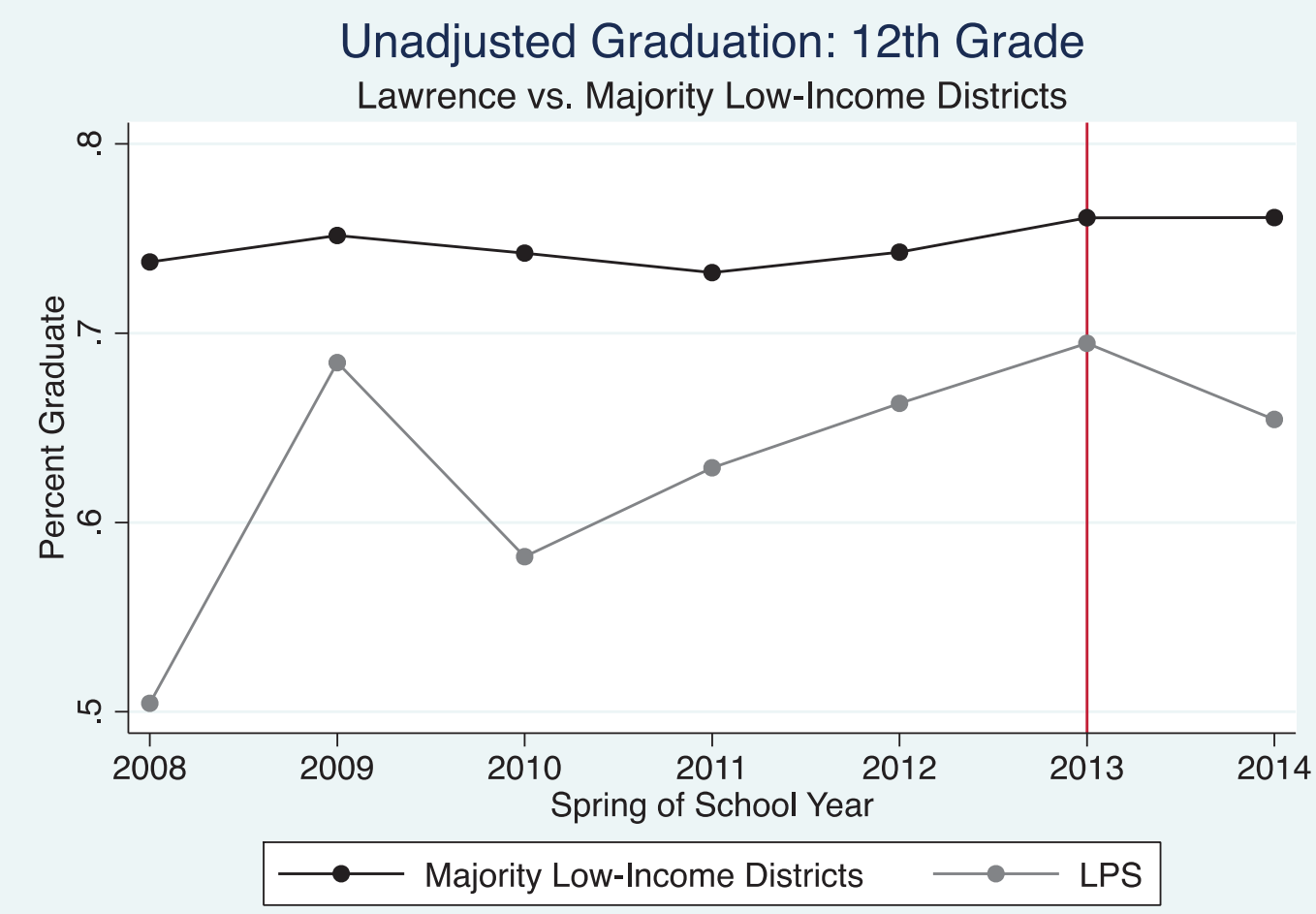

Figure 10. Overall Graduate Rate Among $12^{\text {th }}$ Grade Students 


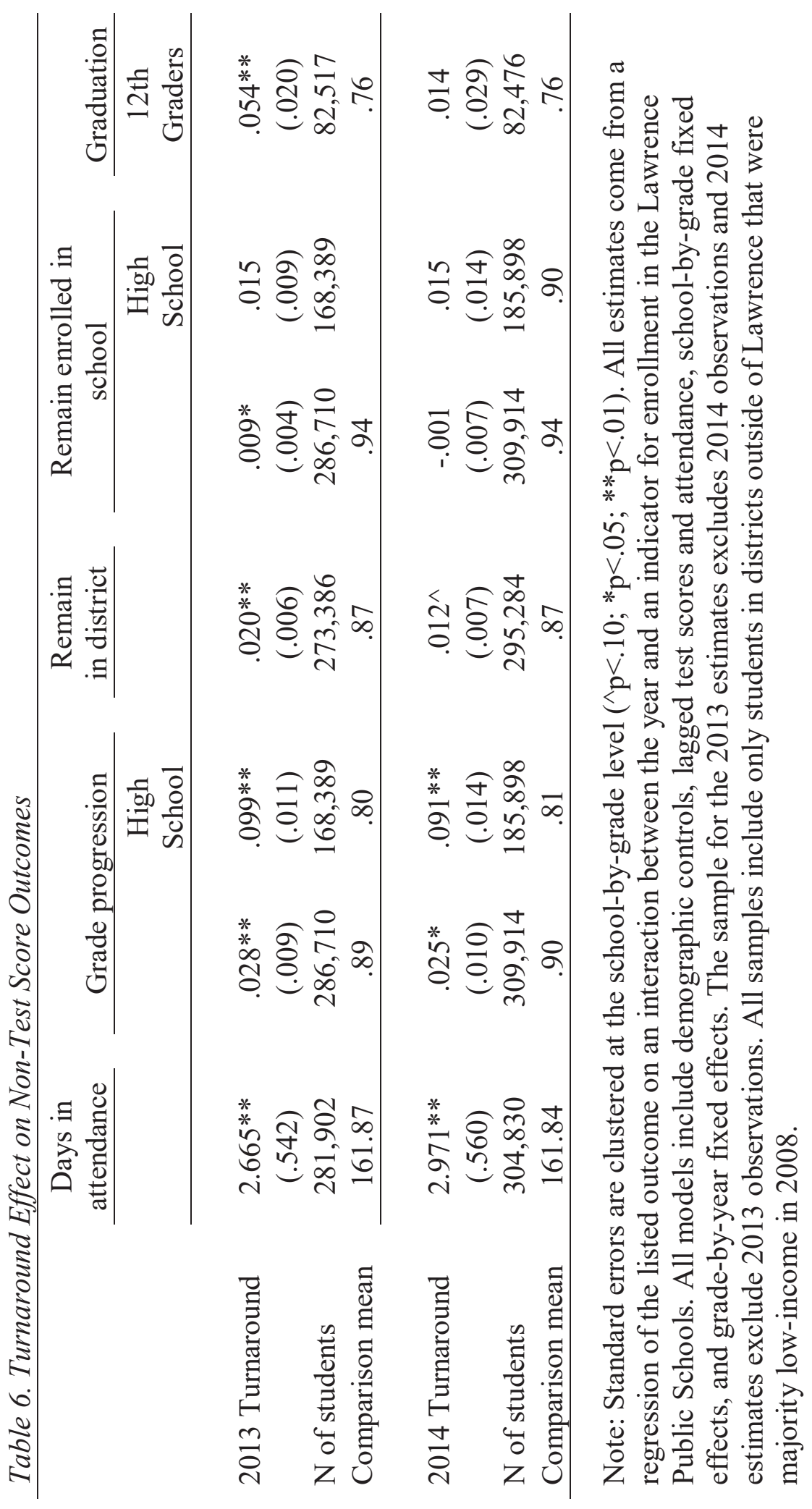




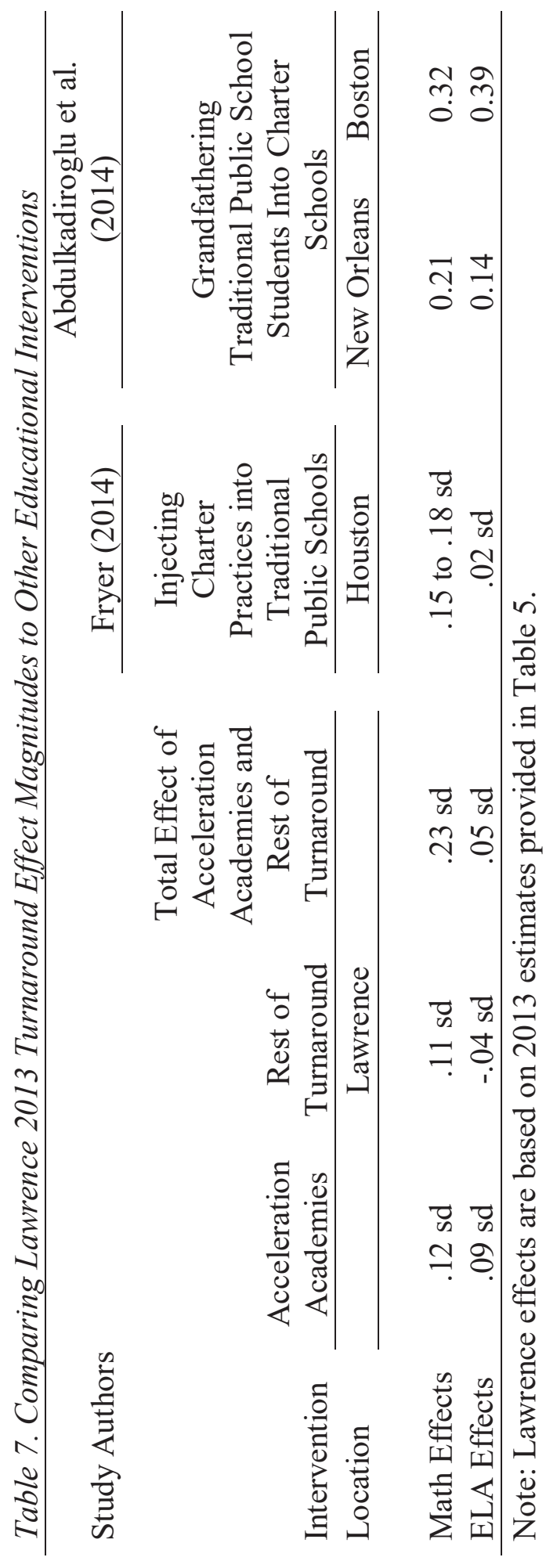




\title{
Appendix
}

\section{Acceleration Academies}

\author{
Unadjusted Math MCAS
}

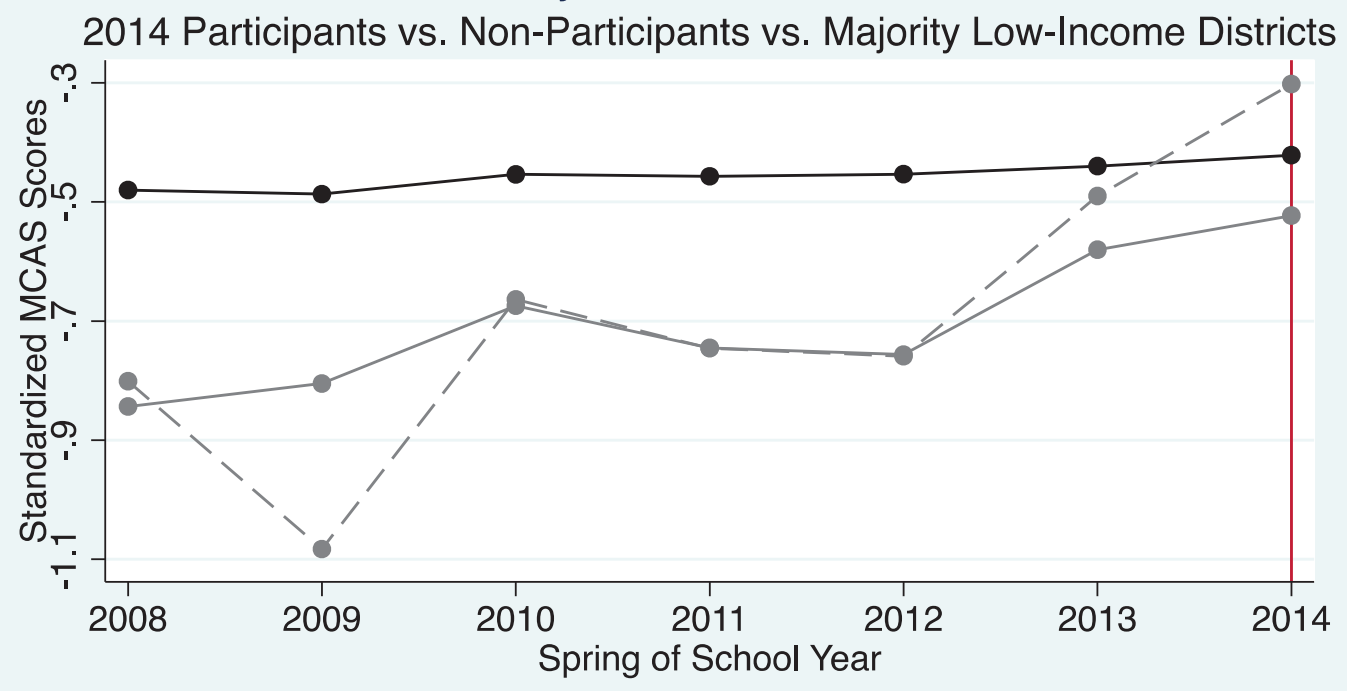

$\longrightarrow$ Majority Low-Income Districts —— LPS Non-Participants $-\rightarrow-$ LPS AA Participants

\section{Unadjusted ELA MCAS}

2014 Participants vs. Non-Participants vs. Majority Low-Income Districts

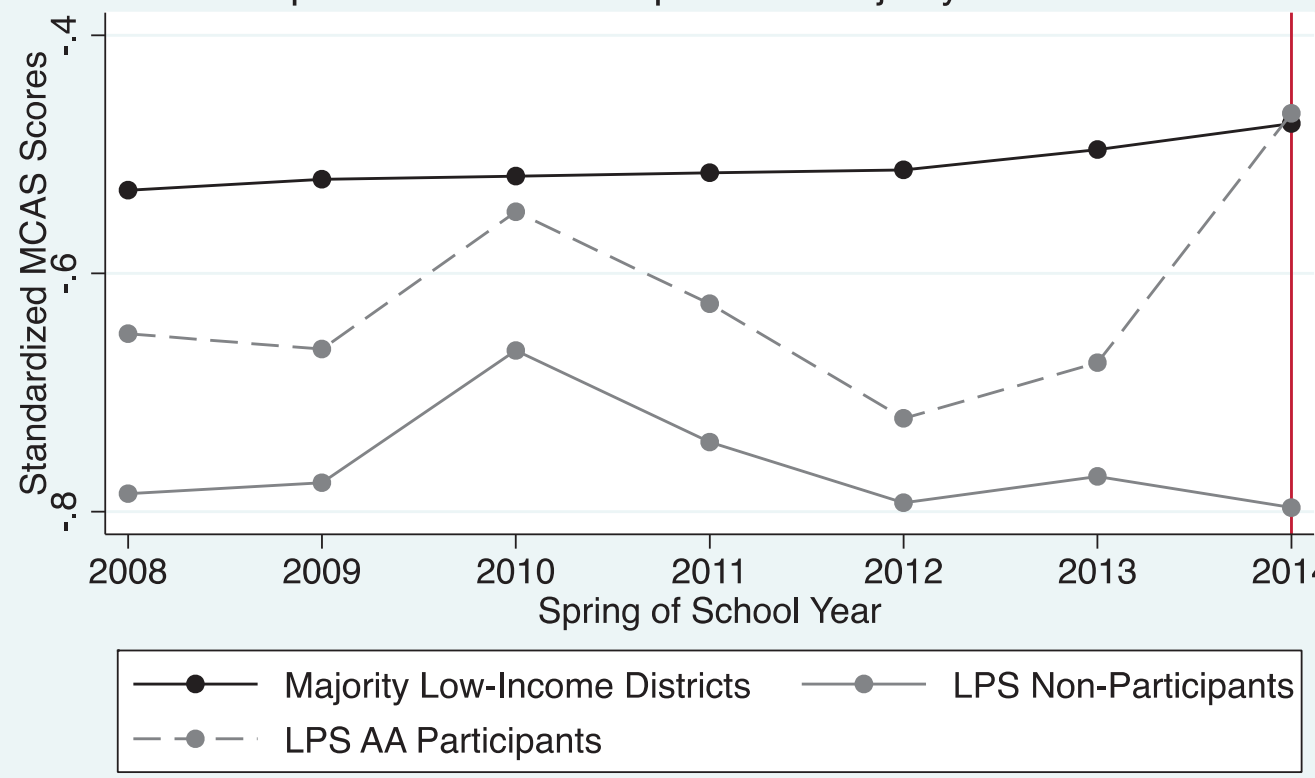

Appendix Figure A. Mean MCAS Scores by 2014 Acceleration Academy Participation 

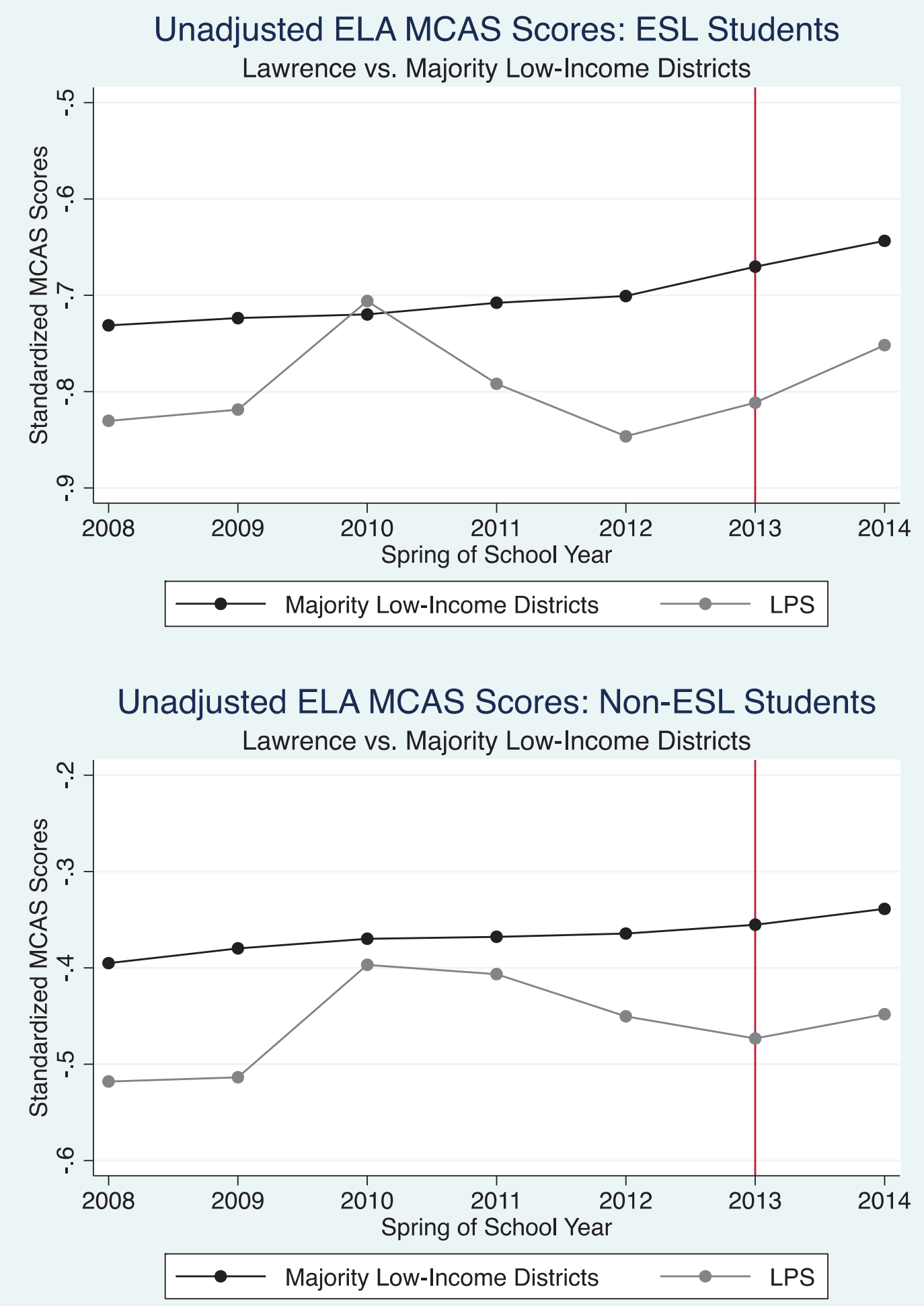

Appendix Figure B. Mean ELA MCAS Scores by ESL Status 


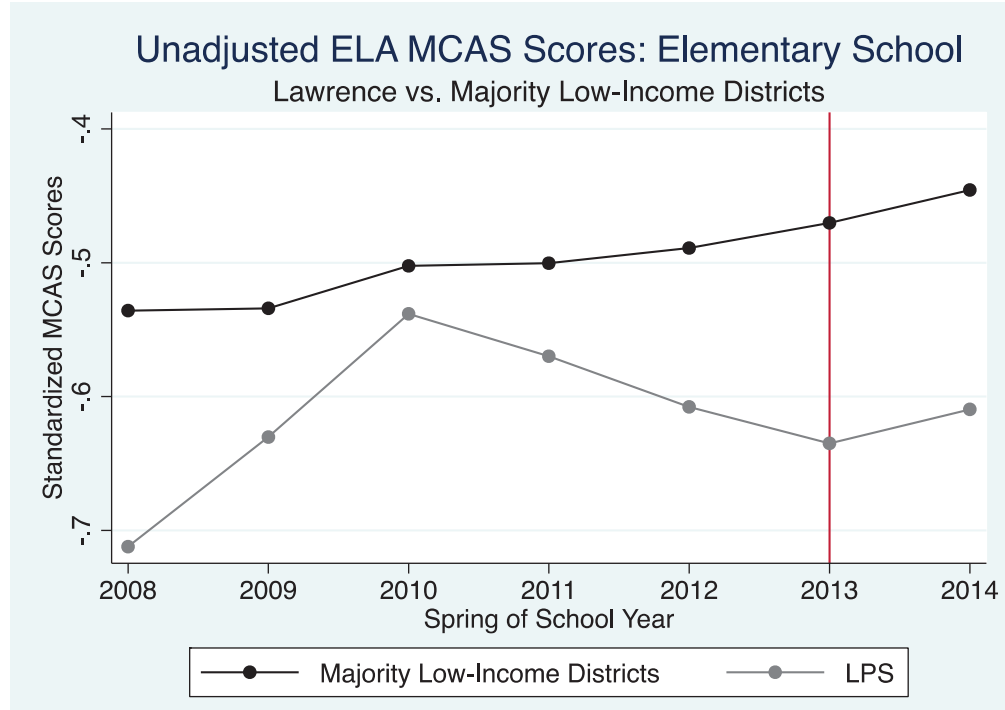

Unadjusted ELA MCAS Scores: Middle School

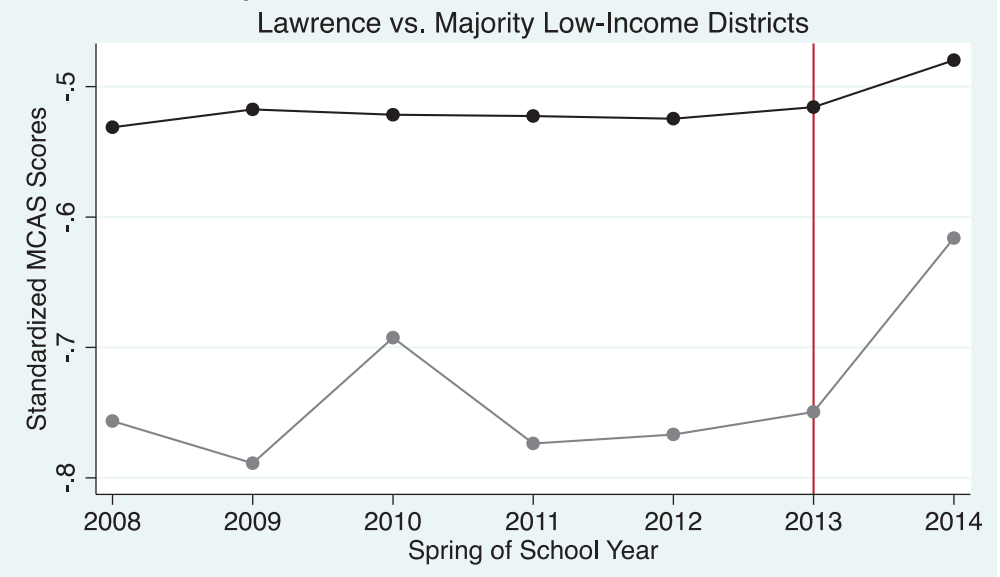

$\longrightarrow$ Majority Low-Income Districts $\longrightarrow$ LPS

Unadjusted ELA MCAS Scores: High School

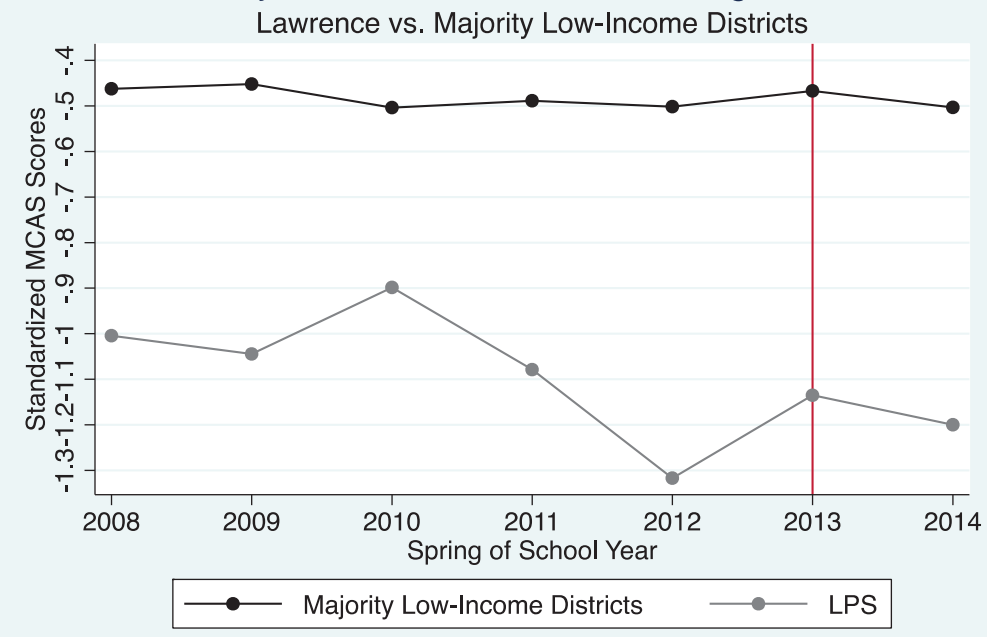

Appendix Figure C. Mean ELA MCAS Scores by Grade Level 


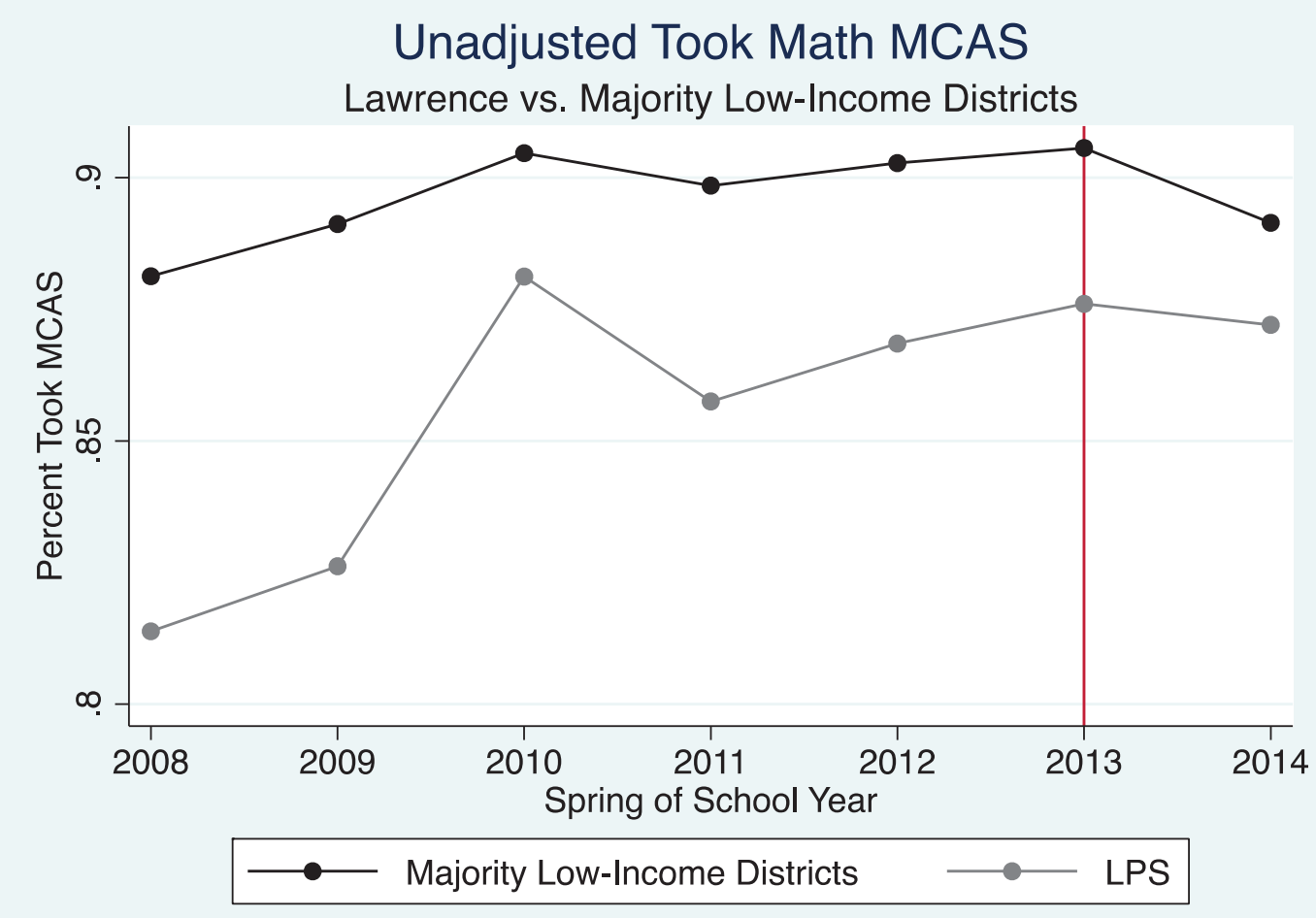

Unadjusted Took ELA MCAS

Lawrence vs. Majority Low-Income Districts

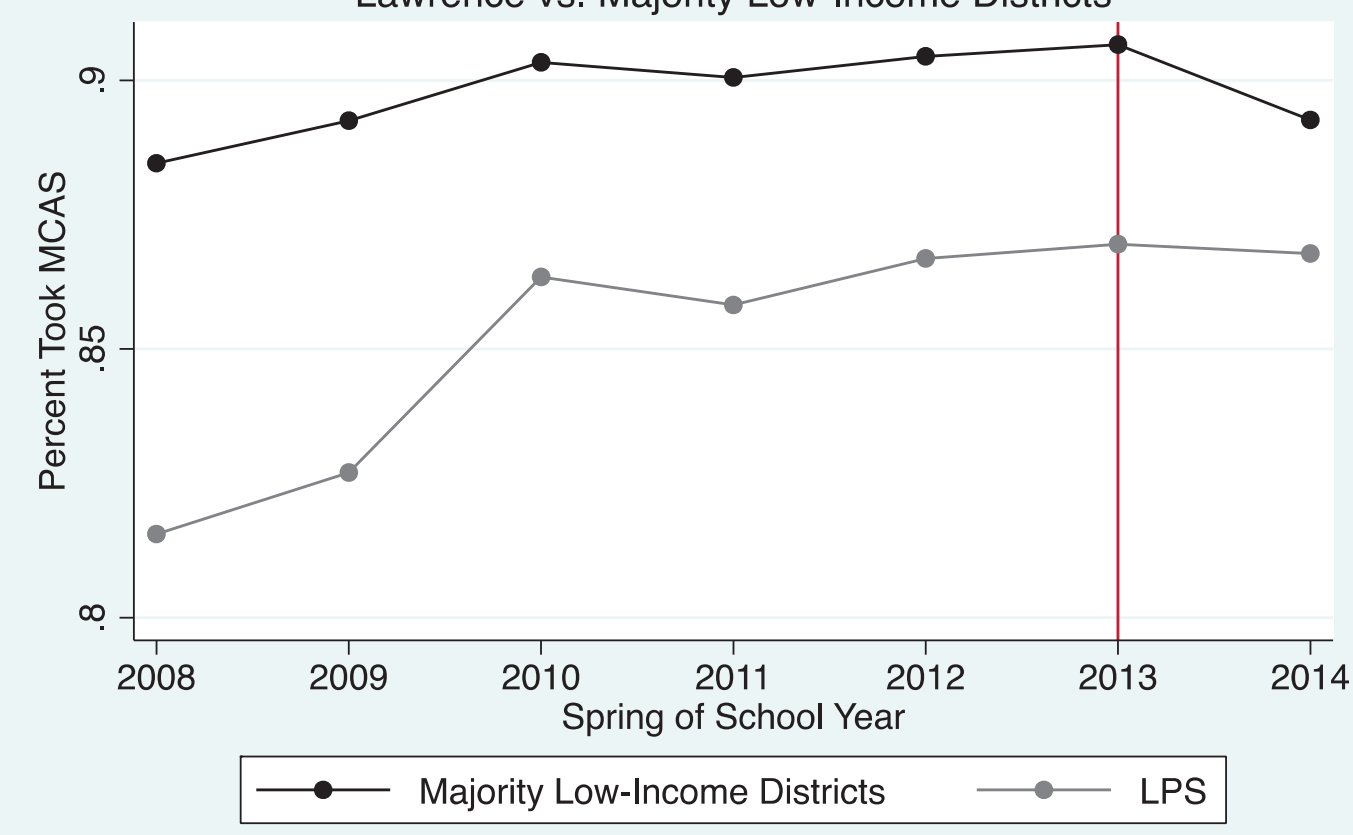

Appendix Figure D. Overall Percent of Students Taking the MCAS Exam 